\title{
LAND SYSTEMS AS SURROGATES FOR BIODIVERSITY IN CONSERVATION PLANNING
}

\author{
Ian Oliver, ${ }^{1,3}$ Andrew Holmes, ${ }^{1,4}$ J. Mark Dangerfield,${ }^{1}$ Michael Gillings, ${ }^{1}$ Anthony J. Pik, ${ }^{1}$ \\ David R. Britton,,${ }^{1}$ Marita Holley, ${ }^{1}$ Margaret E. Montgomery, ${ }^{1}$ Madeline Raison,,${ }^{1}$ Vicki Logan, ${ }^{2}$ \\ Robert L. Pressey, ${ }^{2}$ And Andrew J. Beattie ${ }^{1}$ \\ ${ }^{1}$ Key Centre for Biodiversity and Bioresources, Department of Biological Sciences, Macquarie University, Sydney, \\ New South Wales, 2109, Australia \\ ${ }^{2}$ New South Wales National Parks and Wildlife Service, P.O. Box 402, New South Wales 2350, Australia
}

\begin{abstract}
Environmental surrogates (land classes) for the distribution of biodiversity are increasingly being used for conservation planning. However, data that demonstrate coincident patterns in land classes and biodiversity are limited. We ask the overall question, "Are land systems effective surrogates for the spatial configuration of biodiversity for conservation planning?" and we address three specific questions: (1) Do different land systems represent different biological assemblages? (2) Do biological assemblages on the same land system remain similar with increasing geographic separation? and (3) Do biological assemblages on the same land system remain similar with increasing land system isolation? Vascular plants, invertebrates, and microbiota were surveyed from 24 sites in four land systems in arid northwest New South Wales, Australia. Within each land system, sites were located to give a hierarchy of inter-site distances, and land systems were classified as either "low isolation" (large and continuous) or "high isolation" (small patches interspersed among other land systems).

Each type of land system supported components of biodiversity either not found, or found infrequently, on other land systems, suggesting that land systems function as surrogates for biodiversity, and that conservation-area networks representing land-system diversity will also represent biological diversity. However, the majority of taxa were found on more than one land-system type, suggesting that a large proportion of the plant, arthropod, and microbial biodiversity may be characterized by widespread species with low fidelity to particular land systems. Significant relationships between geographic distance among sites and differences among assemblages were revealed for all taxa except the microbiota. Therefore, as sites on the same land system were located farther apart, the assemblages at those sites became more different. This finding strongly suggests that conservation planning based on land-system diversity should also sample the geographic range occupied by each land system. Land-system isolation was not revealed to be a significant source of variation in assemblage composition. Our research finds support for environmental surrogates for biodiversity in conservation planning, specifically the use of land systems and similarly derived land classifications. However, the need for explicit modeling of geographic distance in conservation planning is clearly indicated.
\end{abstract}

Key words: assemblages; biodiversity surrogates; conservation planning; invertebrates, distribution; land systems; microbiota, distribution; spatial autocorrelation; Sturt National Park, New South Wales, Australia; vascular plants, distribution.

\section{INTRODUCTION}

Conservation planning requires clear choices about the features to be used as surrogates for overall biodiversity in the planning process (Margules and Pressey

Manuscript received 3 June 2002; revised 11 March 2003; accepted 28 May 2003; final version received 10 July 2003. Corresponding Editor: C. A. Wessman.

${ }^{3}$ Present address: Ecosystem Processes and Biodiversity Unit, Department of Infrastructure, Planning and Natural Resources, P.O. Box U245, University of New England, Armidale, New South Wales 2351, Australia.

E-mail: ian.oliver@dipnr.nsw.gov.au

${ }^{4}$ Present address: School of Molecular and Microbial Biosciences, The University of Sydney, Sydney, New South Wales 2006, Australia.
2000, Ferrier 2002; Ferrier et al. 2002a, b). Broadly, there are two types of surrogates used for conservation planning: taxonomic (one taxon or group for another) and environmental (land classes as surrogates for taxa). Tests of taxonomic surrogates have not been encouraging (see Oliver and Beattie 1996a, Oliver et al. 1998, Wessels et al. 1999, Lindenmayer et al. 2002, Lombard et al. 2003 and references therein). In addition, data on species are often not sufficiently widespread or consistent at the spatial scales required by conservation planners. Environmental surrogates, which are based on data mapped from remote sources, often provide surrogate data at the planning scale. In many parts of the world they are the only spatially consistent data available for conservation planning (Noss 1987, Mar- 
gules and Pressey 2000). By necessity, environmental surrogates are now commonly used for conservation planning, either alone or in combination with taxonomic surrogates (see Oliver et al. 1998, Pressey et al. 2000, Ferrier 2002, Ferrier et al. 2002a, $b$, Lombard et al. 2003). Although many environmental surrogates have not been developed with conservation planning in mind (e.g., land systems, soil and geological types) they can sensibly be used for this purpose because they are based on variables believed to be important in determining the spatial distribution of species. This study tests this theory with empirical data.

Among the environmental surrogates used for conservation planning are land systems, defined as "an area or group of areas throughout which there is a recurring pattern of topography, soil and vegetation" (Christian 1958, Mabbutt 1968, Walker 1991:3). Land systems are determined on the basis of 1:50 000 stereo air-photo interpretation, together with reference to geological and topographical maps, and ground traverses for field sampling, validation, and description. Each land system is described in terms of its land units. For example, a dunefield land system may be composed of dune, interdune corridors (swales), and minor drainagedepression land units (Walker 1991). Land systems therefore have a characteristic aerial photographic pattern that is influenced to varying degrees by their geology, relief, topography, and native vegetation. Because most land classifications developed for use as environmental surrogates for biodiversity are derived from these types of remotely sensed data layers, our findings are likely to be broadly applicable and of relevance to conservation planners worldwide.

Land systems have long been utilized for guiding allocation of type and intensity of land use and choice of land management strategies in Australia (see Purdie et al. 1986, Walker 1991, Johnston et al. 1996, Pressey and Taffs 2001a,b) and elsewhere (see Felfili and Da Silva 1993, Kazaklis and Karteris 1993, Lawrence et al. 1993, King 1994, Murgen et al. 1998, Van Wilgen et al. 2000). They have also been used in New South Wales and Queensland (Purdie et al. 1986, Smart et al. 2000, Pressey and Taffs 2001 $a, b$ ) as a surrogate for the spatial distribution of biodiversity in conservation planning. However, our knowledge of the performance of environmental surrogates, in accounting for the distributions of species, is severely lacking (but see Kirkpatrick and Brown 1994, Ferrier and Watson 1997, Wessels et al. 1999, Lombard et al. 2003). Pressey (1994), for example, reviewed five limitations of environmental surrogates. Several exercises in identifying vascular plants and vertebrates of conservation concern in New South Wales were motivated by these limitations (Dickman et al. 1993, Pickard and Norris 1994, Smith et al. 1994), but with the exception of preliminary investigations by Ferrier and Watson (1997), there has been no quantitative assessment of how well land systems match species distributions. This is especially true for microbial and invertebrate biodiversity, "the little things that run the world" (Wilson 1987:342).

Invertebrate and microbial populations are exceedingly large and diverse, making collection of a meaningful sample for comparative purposes across large spatial scales difficult. Recent developments in invertebrate biodiversity assessment have facilitated such studies (see Oliver et al. 2000). In the case of the microbiota, the primary impediment has been a lack of appropriate techniques for meaningful diversity assessment. The historical approach to bacterial classification and identification has been based upon the examination of cell physiology and biochemistry in pure culture. However, the vast majority of microorganisms are not easily brought into pure culture. Over the past decade microbial biodiversity assessment has been revolutionized by the introduction of molecular biology into microbial systematics and ecology (Head et al. 1998).

The basic principle of these new approaches is to reduce complex communities of living cells to samples of a specific gene obtained from each cell. The different approaches vary in their choice of DNA fragment and how they sort the DNA fragments in the sample into different populations. The major factors influencing the choice of DNA fragment are its information content and the ease with which it may be recovered from the target community. By far the most commonly used gene in this strategy is the small subunit ribosomal RNA (16S rRNA). There are presently in excess of 60000 sequences of this gene from cultivated and uncultivated organisms in public databases (Cole et al. 2003). Recovery of genes for community analysis by polymerase chain reaction (PCR) is now a standard technique in microbial ecology. There are two broad strategies for sorting a PCR sample of community DNA into different populations. These are cloning and electrophoretic separation. The former has the advantage that it is equivalent to collection of individual specimens and has inherently higher information content. It is however difficult to process the very large numbers of specimens needed for comparative ecology of microbial communities. In contrast, electrophoretic separation results in the sorting of DNA fragments into populations, rather than individual specimens. Although there is less information content in this method its much greater "processivity" has led to its increasing use in community comparisons (Fromin et al. 2002). Here we have employed cloning to analyze bacterial diversity and electrophoretic separation to analyze fungal diversity. By application of these advances in microbial ecology we examine for the first time the spatial patterns of bacterial and fungal diversity in arid Australia.

Our study integrates measures of diversity at different spatial scales and at different levels of biological organization and enables us to test the general hypothesis that large-scale pattern can be used to interpret fine-scale phenomena (Ettema and Wardle 2002), but 


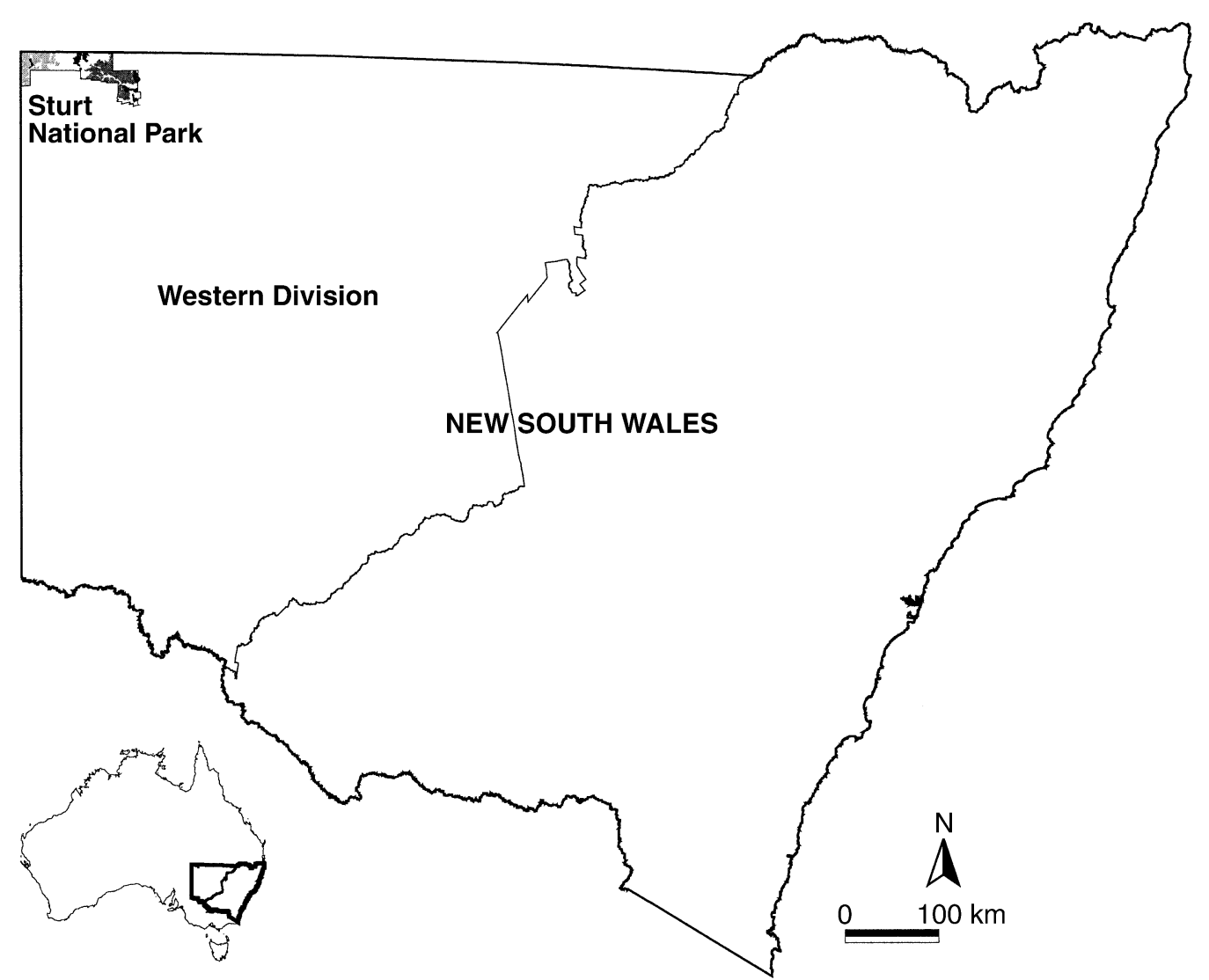

FIg. 1. New South Wales (Australia), the Western Division, and the study area, Sturt National Park.

more specifically we ask the question: "Are land systems effective surrogates for the spatial configuration of biodiversity in conservation planning?" To address this broad question, we sought to answer the following three more specific questions: (1) Do different land systems represent different biological assemblages? (2) Do biological assemblages on the same land system remain similar with increasing geographic separation? and (3) Do biological assemblages on the same land system remain similar with increasing land-system isolation? Biological assemblages are defined as phylogenetically related groups of taxa occurring at the same place at the same time (Fauth et al. 1996). The latter two questions were considered because we hypothesized that the compositional dissimilarity of biological assemblages at survey sites on the same land system would increase with increases in geographic separation and isolation (see Oliver et al. 1998, Ferrier et al. 1999, 2002a, Nekola and White 1999, Condit et al. 2002, Ferrier 2002). If geographic distance and isolation are themselves correlated with change in biological assemblages the efficacy of using land systems alone as surrogates for biodiversity may be compromised.

\section{Methods \\ Study area}

Land use in western New South Wales is predominantly sheep grazing on native rangelands. In terms of conservation, the area has received little attention relative to the eastern parts of the State, with $2.98 \%$ of the Western Division in reserves compared with $9.12 \%$ for the Central and Eastern Divisions (Pressey et al. 2000, Pressey and Taffs 2001a). In addition, climate extremes coupled with human activity and the impacts of feral herbivores and carnivores have resulted in widespread land degradation, resource depletion, and species decline (Allison et al. 1990, Benson 1991, Mitchell 1991, Pickard 1991, Graham 1992, Dickman et al. 1993, Smith et al. 1994, James et al. 1999). One prominent conservation area, Sturt National Park, in the extreme northwest of the State, was used as the study area for this project (Fig. 1). The park is situated $\sim 1000 \mathrm{~km}$ northwest of Sydney and occupies an area of $\sim 3500 \mathrm{~km}^{2}$. The area is described as warm-arid and characterized by low and unreliable rainfall, with an annual average of $227 \mathrm{~mm}$. Daytime temperatures in summer normally exceed $30^{\circ} \mathrm{C}$ and at most times of the year the diurnal temperature variation exceeds $20^{\circ} \mathrm{C}$. The area had been extensively grazed by domestic stock, mostly sheep, for more than 100 years before becoming a National Park in the early 1970s. Despite the removal of domestic stock at that time, the presence of permanent water sources (i.e., small manmade earth dams fed by overland water flow or from artesian water sources) has maintained high kangaroo 


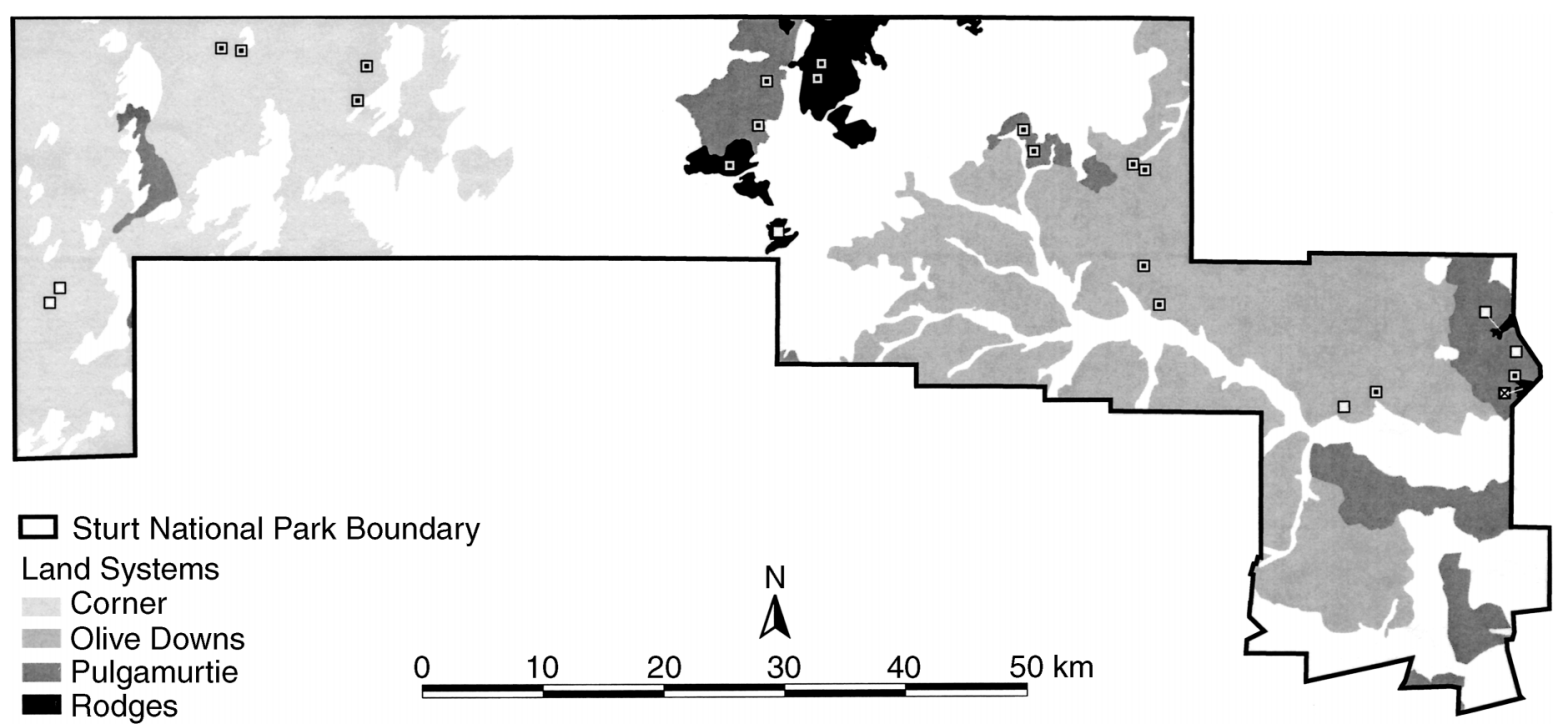

FIG. 2. The four land systems in Sturt National Park on which biodiversity assessments were conducted, and the locations of the twenty-four $750 \times 750 \mathrm{~m}$ study sites. Site symbol key: $\square$, sites that contained $20 \times 50 \mathrm{~m}$ vegetation-survey plot pairs; $\square$, sites that did not contain $20 \times 50 \mathrm{~m}$ vegetation-survey plot pairs; $\bigotimes$, the single $750 \times 750 \mathrm{~m}$ site that contained two $20 \times 50 \mathrm{~m}$ vegetation-survey plot pairs.

numbers and a high grazing pressure. Despite longterm high grazing pressure exotic plant species are uncommon.

Two underlying geologies characterize the landscape of the park. The eastern section is an undulating landscape on Cretaceous Rolling Downs sediments with some pockets of Quarternary colluvials. It is characterized by a strongly sorted soil covered with weatherworn pebbles of silcrete and quartz that form bare sections among the Mitchell grass (Astrebla spp.). The western section comprises late tertiary and Quarternary unconsolidated sediments. It is characterized by sand plains and red dunes averaging $10-15 \mathrm{~m}$ in height, which are vegetated and largely immobile. The sand dunes and plains support a perennial woodland community dominated by sandhill wattle (Acacia ligulata), cabbage-tree wattle (A. cana), mulga (A. aneura), needlewood (Hakea leucoptera), whitewood (Atalaya hemiglauca), and beefwood (Grevillea striata). The shrub layer consists principally of species of Senna, Eremophila, and Dodonea. The Rolling Downs country is largely treeless. The dominant perennial community consists of low shrubs and saltbush (Atriplex spp.), bluebush (Maireana spp.), copperburr (Scleolaena spp.), and tussocks of Mitchell grass (NSW NPWS 1996).

Land-system mapping in New South Wales was undertaken by the New South Wales Soil Conservation Service between 1975 and 1989 (Walker 1991). The mapping program was confined to the leasehold lands of the Western Division, an area of $335667 \mathrm{~km}^{2}$ or $42 \%$ of the State (Fig. 1). Maps were developed from 1: 50000 stereo air-photo interpretation, together with reference to geological and topographical maps, and ground traverses for field sampling, validation, and description. The mapping program described and mapped 251 land systems at a scale of 1:250 000 (Walker 1991). Sturt National Park contains 23 land systems.

\section{Study design}

From the 23 land systems, four were selected that provided the opportunity to test the three questions critical to an assessment of the effectiveness of land systems as surrogates for biodiversity. Two of the land systems, Olive Downs and Pulgamurtie, were on Cretaceous sediments and two, Corner and Rodges, were on unconsolidated sediments. Together, the four land systems represented $42 \%$ of the area of the Sturt National Park (Fig. 2). Corner and Olive Downs were chosen to represent "low isolation" land systems (large contiguous areas), and Pulgamurtie and Rodges were chosen to represent "high isolation" land systems (small patches interspersed among other land-system types, Fig. 2). Six sites were strategically located within each of the four land systems, providing a total of 24 study sites (Fig. 2). They were located on the basis of three considerations. First, to avoid effects of spatial autocorrelation on the analysis of our primary question (assemblage differences among land systems) sites within one land system were located as much as possible to be spatially interspersed among sites from other land systems. The degree to which we were successful in achieving this aim is shown in Fig. 2. Second, to explore correlations between a range of geographic distances and compositional dissimilarity within land systems, we attempted to locate three sets of paired sites (sites within pairs $<5 \mathrm{~km}$ apart) at 15,45 , and $60 \mathrm{~km}$ separation (Fig. 3). The degree to which we were suc- 


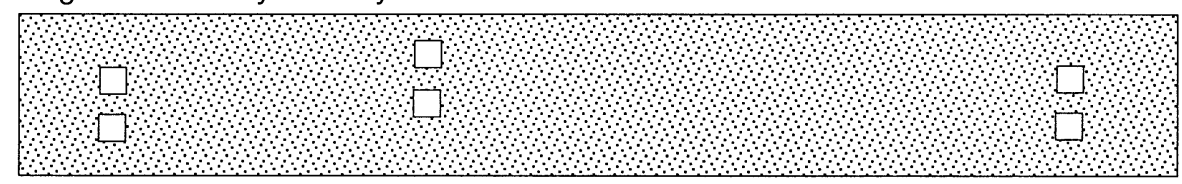

"Low Connectivity" land systems: Rodges and Pulgamurtie

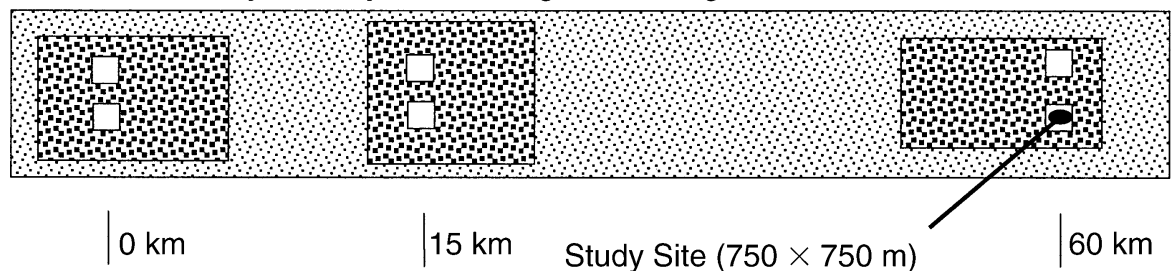

FIG. 3. Design framework used to aid the location of survey sites (not to scale). Specifically, there were three sets of paired sites $(<5 \mathrm{~km}$ apart $)$.

cessful in achieving the desired inter-site distances is illustrated in Fig. 4. Third, sites were located wherever possible to overlie plot pairs earlier surveyed for vascular plants (see below). Seventeen invertebrate and microbial sites overlaid plant-survey plot pairs, one site overlaid two plant-survey plot pairs, and six sites did not overlay plant-survey plot pairs. Therefore, there were 19 plant-survey plot pairs available for analysis (see Fig. 2 and Table 1).

In August 1997 field teams located and marked out the 24 study sites, each of size $750 \times 750 \mathrm{~m}$. Large study sites were chosen for two reasons: because invertebrate and microbial biodiversity sampling is rarely undertaken at such scales, and to provide a large range of distances between sample points for spatial analysis of biodiversity patterns. Within each site we used GPS (global positioning systems, Garmin GPS 12XL [Garmin Corporation, Olathe, Kansas, USA]) to mark out 250-m grids (Fig. 5). In September/October 1997 field teams set out 64 sampling points within each site using standard tape-and-compass techniques (Fig. 5). The study design resulted in 4 land systems $\times 6$ sites $\times 64$ sampling points (arranged in four groups within each site) or a total of 1536 sampling points across the National Park. The size of the study sites, their location, and the arrangement of sampling points also ensured that we represented the internal heterogeneity of land systems (e.g., dunes, swales, drainage channels, vegetation clumps, and micro-topography). This was particularly important for the top-down analyses presented in this paper in which we explore the efficacy of land systems as biodiversity surrogates. However, our design also provides 64 sample points within each site as close as $1 \mathrm{~m}$ and as distant as $1.4 \mathrm{~km}$ for bottomup analyses by which we will explore, in another paper, the determinants and scaleability of spatial patterns in biodiversity.

\section{Biodiversity sampling}

At each of the 1536 sampling points we sampled soil microbiota and ground-active invertebrates. A hole of diameter $10 \mathrm{~cm}$ and depth $10 \mathrm{~cm}$ was excavated with a hand trowel. From the wall of the hole a soil sample was taken horizontally at $8 \mathrm{~cm}$ depth. Where possible this sample was a core of $1 \times 5 \mathrm{~cm}$ obtained using a 5-mL sterile sample vial itself as a borer. At rocky sites the soil sample was collected using a spatula. All soil samples were frozen within $10 \mathrm{~h}$ of collection. A 250$\mathrm{mL}$ polycarbonate sample container (diameter $67 \mathrm{~mm}$, depth $100 \mathrm{~mm}$ ) was then installed in the $10 \times 10 \mathrm{~cm}$ hole with its lip flush with the back-filled ground surface to sample ground-active invertebrates. These pitfall traps contained $150 \mathrm{~mL}$ of mono-ethylene glycol as a preservative and were left in place for $10 \mathrm{~d}$ during the period 22 September to 10 October 1997. After pitfall-trap removal, mono-ethylene glycol was replaced with $80 \%$ ethanol. The 1536 microbial and ground-active invertebrate samples were therefore spatially and temporally coincident. All samples were labeled in the field with dedicated barcodes. There was no rainfall during the sampling period and no significant rain had fallen in the area since the preceding summer (totals: January, $43 \mathrm{~mm}$; February, $142 \mathrm{~mm}$; March-September, $35 \mathrm{~mm}$ ).

Floristic data analyzed in this paper come from a larger, and as yet unpublished, study by two of the authors (R. L. Pressey and V. Logan) and were collected in 1993 after a period of good rainfall. The data from that larger study describe the vascular-plant species present within two plots of size $20 \times 50 \mathrm{~m}$, together with a cover-class estimate for each species (absent, $<5 \%, 5-20 \%, 21-50 \%, 51-75 \%, 76-100 \%)$. For the land systems Olive Downs and Pulgamurtie, plot 1 was located in a drainage tract with plot 2 nearby on an interfluve or upland land unit. In Corner and Rodges land systems, plot 1 was located on a dune crest with plot 2 in a nearby alluvial corridor or plain. Plot pairs, therefore, captured some of the internal heterogeneity of the four land systems. For the present study the midpoints of the cover classes were averaged for each species across the two plots and this figure used in the 

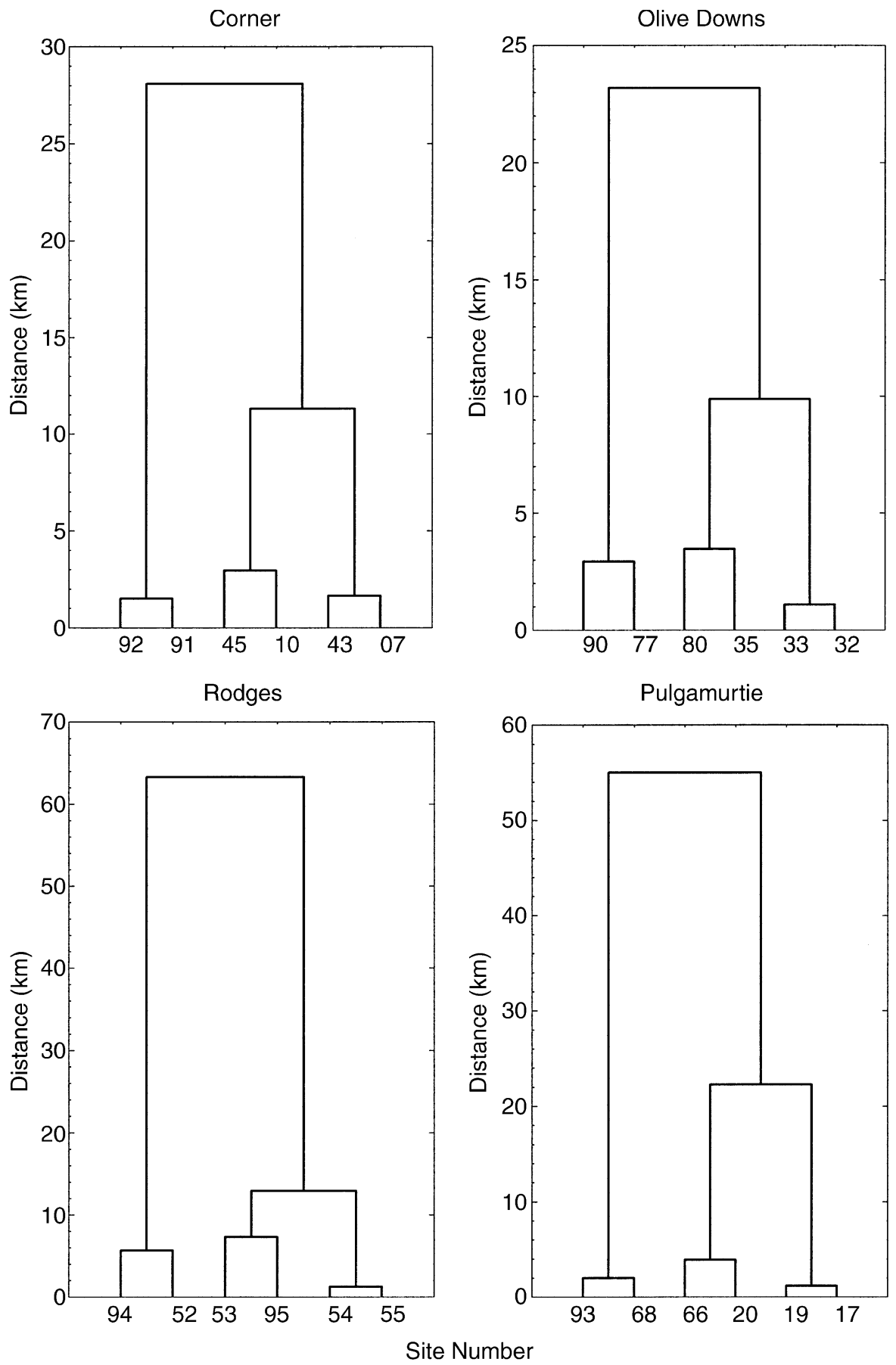

FIG. 4. The realized spatial hierarchy of distances between $750 \times 750 \mathrm{~m}$ site locations, by land system. Dendrograms are based on Euclidean distance between sites and unweighted pair-group average (see Table 1).

analyses. Data from plot pairs were, therefore, pooled prior to analysis (unpooled floristic data are to be analyzed in a separate paper). Three introduced plant species were recorded. They were present in low cover and were included in the analyses. When the larger invertebrate and microbial study sites overlapped vegetation plots (18 out of 24 sites, see Table 1) the 750 $\times 750 \mathrm{~m}$ study site was located so that one densely sampled sub-plot corner overlapped vegetation plot 1 . This provided floristic, invertebrate, and microbial data coincident in space (not time) for an area of $20 \times 20$ $\mathrm{m}$ (10 sample points within each site). Our biodiversity sampling program also provided for the investigation of patterns of biodiversity at different scales of bio- 
TABLE 1. Details of the $750 \times 750 \mathrm{~m}$ sites sampled for arthropods, microbiota, and vascular plants in the four different land systems in Sturt National Park, New South Wales, Australia.

\begin{tabular}{|c|c|c|c|c|c|}
\hline \multirow{3}{*}{$\begin{array}{l}\text { Site } \\
\text { no. } \dagger\end{array}$} & & & \multirow{3}{*}{$\begin{array}{l}\text { Fig. } 2 \\
\text { symbols }\end{array}$} & \multicolumn{2}{|c|}{ Sampled for } \\
\hline & \multicolumn{2}{|c|}{ GPS location } & & \multirow{2}{*}{$\begin{array}{c}\text { Arthropods } \\
\text { and } \\
\text { microbiota }\end{array}$} & \multirow{2}{*}{$\begin{array}{c}\text { Vascula } \\
\text { plants }\end{array}$} \\
\hline & Easting & Northing & & & \\
\hline \multicolumn{6}{|c|}{ Corner } \\
\hline 07 & 518961 & 6789022 & $\square$ & yes & yes \\
\hline 10 & 528606 & 6784868 & $\cdot$ & yes & yes \\
\hline 43 & 517319 & 6789259 & $\square$ & yes & yes \\
\hline 45 & 529378 & 6787714 & $\cdot$ & yes & yes \\
\hline 91 & 502942 & 6768185 & $\square$ & yes & no \\
\hline 92 & 503793 & 6769437 & - & yes & no \\
\hline \multicolumn{6}{|c|}{ Olive Downs } \\
\hline 32 & 592650 & 6779441 & $\square$ & yes & yes \\
\hline 33 & 593629 & 6778966 & $\square$ & yes & yes \\
\hline 35 & 593485 & 6771006 & 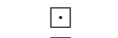 & yes & yes \\
\hline 77 & 612702 & 6760479 & $\square$ & yes & yes \\
\hline 80 & 594773 & 6767786 & $\cdot$ & yes & yes \\
\hline 90 & 610035 & 6759251 & $\square$ & yes & no \\
\hline \multicolumn{6}{|c|}{ Pulgamurtie } \\
\hline 17 & 584105 & 6782141 & 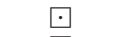 & yes & yes \\
\hline 19 & 584207 & 6780977 & 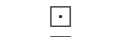 & yes & yes \\
\hline 20 & 561902 & 6782477 & $\square$ & yes & yes \\
\hline 66 & 562461 & 6786362 & $\square$ & yes & yes \\
\hline 68 & 624182 & 6761812 & $\cdot$ & yes & yes \\
\hline 93 & 624322 & 6763813 & $\square$ & yes & no \\
\hline \multicolumn{6}{|c|}{ Rodges } \\
\hline 51 & 625300 & 6760800 & & & yes \\
\hline 52 & 624915 & 6760861 & Х & yes & yes \\
\hline 53 & 559246 & 6778884 & $\square$ & yes & yes \\
\hline 54 & 567000 & 6787815 & $\cdot$ & yes & yes \\
\hline 55 & 566662 & 6786597 & 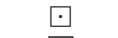 & yes & yes \\
\hline 94 & 623956 & 6766436 & $\square$ & yes & no \\
\hline 95 & 563574 & 6772982 & $\square$ & yes & no \\
\hline
\end{tabular}

Note: The $750 \times 750 \mathrm{~m}$ invertebrate and microbial study site 52 overlapped the two pairs of $20 \times 50 \mathrm{~m}$ vascular-plant survey plots 52 and 51 that were separated by $400 \mathrm{~m}$ only. The two vascular-plant survey plot pairs were analyzed separately (after data were pooled within each pair).

$\dagger$ Site numbers below 90 are those used by R. L. Pressey and V. Logan in a larger (as yet unpublished) study on vascular plants.

$\ddagger$ UTM/UPS projection, zone 56J, Australian Geodetic 1984. Easting and Northing are given for the center of each $750 \times 750 \mathrm{~m}$ site.

logical organization, from the "coarse" to the "fine" in the order: bacterial phyla, invertebrate orders, fly families, ant genera, fungal ITS (internal transcribed spacer) types, ant and fly morphospecies, and plant species (see following).

\section{Sample processing}

Invertebrates.-The Key Centre for Biodiversity and Bioresource's virtual biodiversity assessment facility, BioTrack (Macquarie University, Sydney, New south Wales, Australia) was used to fast-track invertebrate processing from the 1536 samples. The system utilizes the most recent developments in bioinformatics, including: barcode technology for the rapid and accurate input and retrieval of sample and specimen record codes; capture and storage of full-color, high-definition images of voucher specimens, and their taxonomic characters, for fast and accurate on-screen identification of morphospecies; and a powerful relational biodiversity database management system, Biota (Colwell 1996) for the storage, manipulation, retrieval, and transfer of specimen-based biodiversity data. Development and application of the BioTrack system was critical to the rapid and accurate identification of morphospecies within the project's resources. Further details on the BioTrack system and sample-processing protocols can be found in Oliver et al. (2000).

Invertebrates were extracted from pitfall traps and identified to major goups (mainly orders), thus representing major functional as well as phylogenetic distinctions. Due to the numerical dominance of Formicidae (ants) and Diptera (flies and mosquitoes) in the pitfall-trap samples (108608 or $60 \%$ of all specimens caught), ants and Diptera (referred to as "flies" hereafter) were identified further. Initial identification of ants to genus and flies to family was conducted by some of us (A. J. Pik and D. R. Britton, respectively) with subsequent verification by specialist taxonomists. Further identification to morphospecies by the same biodiversity technicians used the rapid biodiversity assessment protocols reported in Oliver and Beattie $(1993,1996 b)$ and utilized the BioTrack on-screen identification facility (Oliver et al. 2000). Ant morphospecies were verified by specialists who identified inconsistencies in identification within the genus $\mathrm{Mel}$ ophorus. Accurate identification of species within this genus frequently requires mounting of specimens (Alan Andersen, personal communication 1998), which was beyond the project's resources. Consequently, all morphospecies from the genus Melophorus were excluded from analyses at morphospecies level ( $\sim 6 \%$ of all ant specimens), but remained in all genus-level analyses. Fly morphospecies were not verified by the taxonomic specialist due to D. R. Britton's experience with this taxon.

Microbiota.-Soil-sample mass ranged from 8 to $12 \mathrm{~g}$. Samples were homogenized in a sterile mortar and pestle before removal of a 400-mg subsample for DNA extraction. Total DNA was extracted using the Fastprep procedure. Cell lysis in this method is achieved by a bead beating method and DNA purified by binding to a silica matrix. The protocol is described fully in Yeates and Gillings (1998). Final yield of DNA in $160 \mu \mathrm{L}$ was estimated as $2.5 \mu \mathrm{g}$. Average molecular mass of the DNA was $>10$ kilobases $(\mathrm{kb})$. The same DNA samples were used for both fungal and bacterial diversity analyses.

Bacterial Diversity.-

a) Contruction of $16 \mathrm{~S}$ rDNA clone libraries. - Sixtyfour soil samples were selected for analysis. These were the 0-, 1-, 5-, and 20-m sample points from one transect within one $250 \times 250 \mathrm{~m}$ sub-plot within Corner sites 7, 10, 43, 91; Olive Downs sites 33, 77, 80, 90; Pul- 


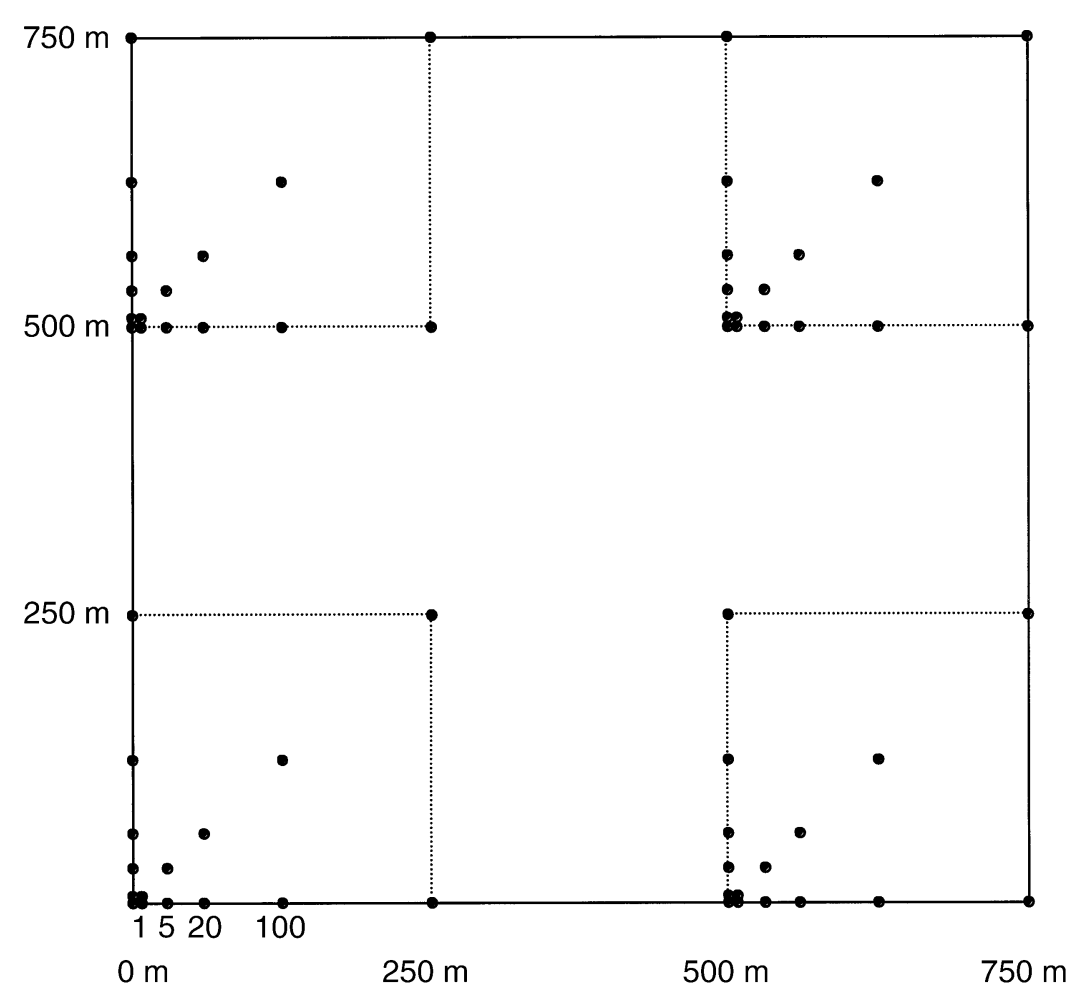

FIG. 5. The spatial arrangement of sample points within study sites (not to scale).

gamurtie sites 19, 20, 66, 68; and Rodges sites 52, 53, 54, 55 (see Fig. 4, Table 1). There were therefore 16 samples from each land system analyzed for bacterial diversity. Bacterial 16S rRNA genes were amplified from the soil samples using the primer set f27, r1492. The PCR (polymerase chain reaction) amplicons were ligated into the pCRII vector supplied with the T/A cloning kit (Invitrogen, Carlsbad, California, USA) according to the manufacturer's instructions. Individual clones were transferred into 384 well microtitre trays (Nunc, Naperville, Illinois, USA) for storage or onto nylon membranes (Hybond-N; Amersham, Piscataway, New Jersey, USA) for analysis (Holmes et al. 2000).

b) Probe analysis of clone libraries. - The relative abundance of eight bacterial populations was deter- mined using phylogenetic group-specific oligonucleotide probe in membrane hybridization experiments. The target groups for each probe and the hybridization temperatures used are given in Table 2. To correct for error in the cloning or membrane transferral processes, hybridization with a universal control probe was performed. The relative abundance of each bacterial population was recorded as the percentage of clones that were positive with the control. These data were converted to integers for subsequent analyses (see Analyses: Do different land systems, below).

Fungal Diversity.-

a) Amplification of the ribosomal ITS region.-All 1536 soil samples were analyzed for fungal diversity. The internal transcribed spacer region (ITS) of the ri-

TABLE 2. Phylogenetic group-specific probes used to identify bacterial higher taxa.

\begin{tabular}{lll}
\hline \hline Probe name & \multicolumn{1}{c}{ Sequence } & $\begin{array}{c}\text { Phylogenetic group targeted } \\
\text { by the probe } \dagger\end{array}$ \\
\hline HighGC280r & CTCTCAGGCCGGCTACCCGTC & $\begin{array}{c}\text { Probe } \\
\text { condition } \\
\left({ }^{\circ} \mathrm{C}\right) \ddagger\end{array}$ \\
Ffer314r & GCCCGTGTCTCAGTGCCCGTG & Subclass: Actinobacteridae \\
Yacido724r & GCCCAGCAACCCGCCTTCGCC & Order: Flavobacteriales \\
CFB319r & TGGTCCGTATCTCAGTAC & Subclass: Acidobacteria group 4 \\
Aacido717r & AAGCCGTCTACACCACAGGTG & Phylum: Bacteroidetes \\
Aproteo687r & AATATCTACGAATTCACCTCT & Subclass: Acidobacteria group 3 \\
Rub749r & CTTTCGCGTCTCAGCGTCAGG & Subclass: $\alpha$-Proteobacteria \\
LGC356b & GCGGAAGATTCCCTACTGC & Subclass: Rubrobacteridae \\
U531f & GTGYCAGCMGCCGCG & Phylum: Firmicutes \\
\hline
\end{tabular}

$\dagger$ Terminology is according to Garrity and Holt (2001).

$\$$ Probe condition is the wash temperature in $2 \times$ SSC buffer at which the reported data were obtained. 
bosomal RNA genes was amplified using the primers SSU1758 (GTCATTTAGAGGAAGTAAAAGTCG) and 58S8 (CAGAACCAAGAGATCCGTTGTTG), targeting the small subunit rRNA and 5.8S rRNA genes, respectively. The thermal profile was $94^{\circ} \mathrm{C} 3 \mathrm{~min} ; 94^{\circ} \mathrm{C}$ $30 \mathrm{~s}, 62^{\circ} \mathrm{C} 15 \mathrm{~s}, 72^{\circ} \mathrm{C} 60 \mathrm{~s}(35$ cycles $) ; 72^{\circ} \mathrm{C} 5 \mathrm{~min}$.

b) Analysis of PCR products.-The ITS region is a highly variable sequence fragment bounded by strongly conserved genes. PCR products were separated into populations of the same size by polyacrylamide gel electrophoresis (PAGE). PAGE was performed in 5\%, ultrathin $(0.1 \mathrm{~mm})$ polyacrylamide gels at $1200 \mathrm{~V}$ for 60 min with laser detection. In the resulting electropherogram each band represents a different fungal population (cf. invertebrate morphospecies). The intensity of the bands represents the relative abundance of each population. Data were analyzed using the RFLPscan package (Scanalytics, Fairfax, Virginia, USA) to calculate the length in base pairs and intensity of each band. This gave a data set where each taxon was identified as a population of DNA fragments of specific length and its relative abundance determined within each sample. These data were treated in the same manner as the invertebrate morphospecies data for subsequent analyses.

\section{Analyses}

Do different land systems represent different biological assemblages?-We hypothesised that different land systems would support different biological assemblages. The attributes we used to characterize the plant, invertebrate, and microbial communities were richness and composition of assemblages. All available samples within sites ( $n=2$ for plants, $n=4$ for bacteria, and $n=64$ for invertebrates and fungi) were pooled for each taxonomic group prior to analyses. Richness was calculated as the total number of unique taxa recorded from all available samples within sites at a range of taxonomic levels from the "coarse" to the "fine" in the order: bacterial phyla, invertebrate orders, fly families, ant genera, fungal ITS types, fly morphospecies, ant morphospecies and plant species. Analysis of variance (ANOVA) tested for statistical differences in richness among land systems within each taxon. ANOVAs, tests for homogeneity of variance (Cochran's), and post-hoc multiple comparisons (Student-NewmanKeuls) were performed using Gmav5 (Underwood 1995).

Analyses of differences between assemblages (compositional dissimilarity) among land systems used transformed abundance, or cover-class mid-point data. Prior to these analyses, invertebrate ordinal, ant generic, and ant morphospecies abundance data were double-square-root transformed $\left(x^{0.25}\right)$, and fly family, fungal ITS data, and fly morphospecies data were squareroot transformed $\left(x^{0.5}\right)$. The different transformations were applied to reduce the range of abundance data for each taxon to approximately 0-10 (Clarke and War- wick 2001). These transformations were used to downweight the very-abundant taxa (some ant morphospecies were represented at sites by several thousand individuals) so that analyses detected differences in composition rather than differences in abundance. We did not transform to presence-absence data as we did not want to totally exclude the influence of the abundance distributions in characterizing assemblages from different land systems. Bacterial data, which were initially expressed as percentages of the total number of clones retrieved in the relevant library (range: $0.1 \%$ to $20 \%$ where the taxon was detected), were multiplied by 10 to convert to integers.

The statistical relationship between compositional dissimilarity and land-system type was first analyzed across all sites by partial Mantel correlation to partition out variance that may have been attributable to geographic distance among sites rather than land-system type. We used the method of Smouse et al. (1986) and the R package (Legendre and Vaudor 1991) to calculate the standardized partial Mantel statistic $r$ between the matrix of compositional-dissimilarity measures (BrayCurtis) among sites and a model matrix that contained 0s (zeros) where pairs of sites were from the same land system and 1s (ones) where sites were from different land systems (Legendre and Fortin 1989). The analysis was conditional on a third matrix containing the geographical distance among sites. Geographical (Euclidean) distances were calculated using the Australian map grid eastings and northings of study-site centers (Table 1$)$, but were transformed $\left(\log _{10} x\right.$, where $x$ was the distance between two sites, in kilometers). The statistical significance of $r$ was determined after 9999 random permutations following the method of Hope (1968; see Legendre and Vaudor 1991).

The analysis described above revealed the presence or absence of a statistical relationship between compositional dissimilarity and land system type conditional on geographic distance among sites. To determine the location of differences (post-hoc multiple comparisons) we used analysis of similarities with 20000 random permutations (ANOSIM within PRIMER, Carr 1994). $P$ values were corrected to an experimentwise $\alpha=0.05$ by Bonferonni correction ( $\alpha$ divided by the number of comparisons, 0.05/6; see Day and Quin 1989).

Following these statistical tests we determined the importance of differences among land systems to conservation planning. To do this we calculated the proportion of fungal ITS types, ant and fly morphospecies, and plant species shared between land systems using presence-absence data and the Jaccard index, $\mathrm{SJ}=C /$ $(A+B-C)$ where $\mathrm{SJ}$ is the similarity index of Jaccard, $C$ is the number of taxa shared by the two land systems, and $A$ and $B$ are the total number of taxa (richness) recorded from each land system (Jongman et al. 1995).

Do biological assemblages on the same land system remain similar with increasing geographic separa- 
tion?-We hypothesised that as geographic distance between assemblages increased, compositional dissimilarity would also increase, that is, assemblages on the same land system would become less alike the further they were apart. To test for the presence of such a correlation across all sites, we again generated standardized partial Mantel correlation coefficients (as above) but this time partitioned out the effect of landsystem type. We further explored these relationships using the standardized Mantel statistic but restricted each analysis to the six sites within each land system.

Following the tests for statistically significant relationships between geographic distance and compositional dissimilarity within land systems we determined the importance of those relationships to conservation planning. We again used presence-absence data and the Jaccard index. However in this case, we exploited the hierarchical nature of site locations (Fig. 4) and calculated the average proportion of fungal ITS types, ant and fly morphospecies, and plant species within land systems shared among sites separated by small distances $(2.0-4.8 \mathrm{~km})$, medium distances (9.9-22.3 $\mathrm{km})$, and large distances $(23.2-63.3 \mathrm{~km})$. For these analyses we used $\mathrm{SJ}=C /(A+B-C)$, where $\mathrm{SJ}$ is the similarity index of Jaccard, $C$ is the number of taxa shared by two sites within a land system, and $A$ and $B$ are the total number of taxa (richness) recorded from each of the two sites being compared within the land system (Jongman et al. 1995). If the rate of change in compositional dissimilarity with increasing distance was high, the average proportion of taxa shared among distant sites would be much lower than for nearby sites.

Do biological assemblages on the same land system remain similar with increasing land-system isolation?-We hypothesized that as the isolation between land systems increased the compositional dissimilarity of assemblages would also increase, that is, assemblages on the same land system are less alike the more isolated they become. Both Corner and Olive Downs were chosen to represent low-isolation land systems (large continuous areas), and Pulgamurtie and Rodges were chosen to represent high-isolation land systems (small patches interspersed among other land-system types, Fig. 2). If land-system isolation as defined here presents a barrier to organism, gamete, or propagule dispersal then the rate of change in biological assemblages with geographical distance may be expected to be greater when land-system connectivity is low. To explore this relationship we calculated least-squares regression coefficients for those taxon-land system combinations that reported statistically significant correlations between compositional dissimilarity and geographic distance. We expected to find larger regression coefficients (steeper slope of fitted straight line) for the high-isolation land systems (Rodges and Pulgamurtie) compared with the low-isolation land systems (Corner and Olive Downs). Difference between regression coefficients were tested with one-tailed $t$ tests of the form
$H_{\mathrm{o}}$ : regression coefficient for low-isolation land systems $\geq$ regression coefficient for high-isolation land systems, and $H_{\mathrm{a}}$ : regression coefficient for low-isolation land systems $<$ regression coefficient for highisolation land systems $(\alpha=0.05)$. Calculation of regression coefficients and tests for significance used Zar (1984:295). Significantly larger regression coefficients for assemblages on high-isolation land systems would indicate a greater rate of change in compositional dissimilarity with geographic distance for land systems with isolated occurrences.

\section{RESUlts}

At the coarse taxon level, bacterial probes tested for the presence of 8 phyla, and 33 invertebrate major groups (called "orders" hereafter), 36 fly families, and 23 ant genera were recorded. At the fine taxonomic level, the rich biodiversity of the region was revealed, with 56 fungal ITS (internal transcribed spacer) types, 304 fly morphospecies, 208 ant morphospecies (from 24 sites), and 187 vascular plant species (from 19 plot pairs) recorded.

\section{Do different land systems represent different biological assemblages?}

At the coarse taxonomic levels, there were no significant differences between the richness of bacterial phyla or fly families among the four land systems (Fig. 6). There was a gradual increase in richness of arthropod orders from Corner, Rodges, Olive Downs, to Pulgamurtie with significant statistical differences observed between Corner and Pulgamurtie. There was a clear effect of geology on the richness of ant genera with significantly more genera recorded from the unconsolidated sediments (Corner and Rodges) than the Cretaceous sediments (Olive Downs and Pulgamurtie). There were, however, no differences in the richness of ant genera between land systems within the same geology.

At the fine level of taxonomic resolution there were differences in richness between land systems for fungal ITS types and fly morphospecies but SNK multiplecomparison tests did not discretely separate all land systems (Fig. 7). Ant morphospecies data revealed significant differences in richness between all land systems, but there were no differences in the richness of plants among land systems.

Significant standardized partial Mantel correlations (conditional on geographic distance among all 24 sites) revealed that land systems accounted for significant variation in compositional dissimilarity for all taxonomic groups except bacterial phyla (Table 3). Amounts of variation explained ranged from as little as $4 \%$ for the fungal ITS types to as much as $48 \%$ for ant morphospecies (partial $r^{2}$, Table 3 ). ANOSIM posthoc multiple comparisons found assemblages of invertebrate orders, ant genera, and fungal ITS types to be significantly different between geologies but not be- 


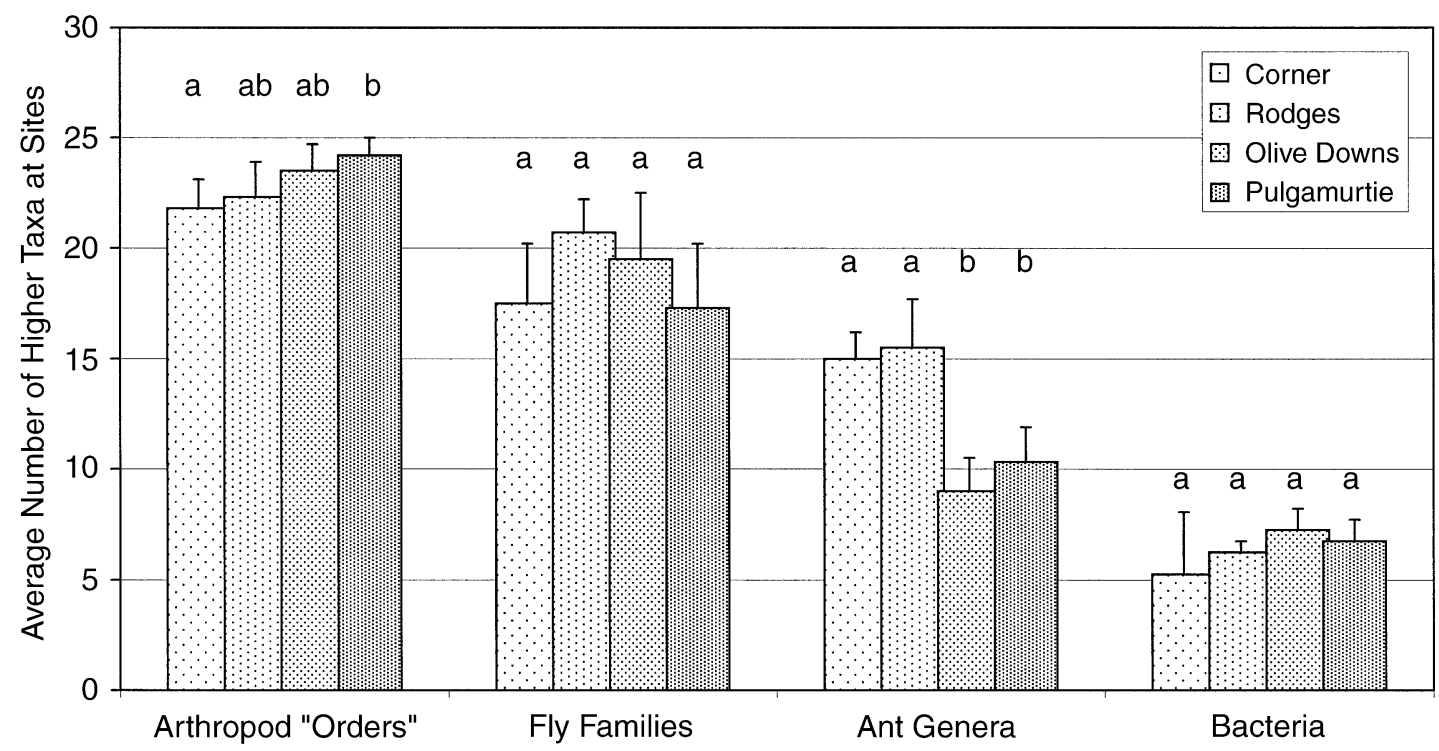

FIG. 6. Differences in assemblage richness between land systems at a coarse level of taxonomic resolution. Within each assemblage, histogram bars with the same lowercase letter are not significantly different at $P<0.05$ according to post hoc multiple comparisons (SNK test); error bars show 1 SD above the mean.

tween land systems within geology. Significant differences in the composition of assemblages were revealed among all four land systems for fly families, fly and ant morphospecies, and for plant species (Table 3).

Despite statistically significant differences in assemblages among land systems the biological magnitude of these differences was not particularly high (Table 4). Very few fungal ITS types were found on only one land system ("Number of taxa recorded unique to a land system" Table 4) and $13-32 \%$ of fly and ant morphospecies and plant species recorded within land systems were unique to those land systems. In other words, many taxa were shared among land systems ("Proportion of taxa shared" Table 4). For example, these proportions varied between 0.72 and 0.87 for fungal ITS types, $0.38-0.49$ for fly morphospecies, $0.17-0.42$ for ant morphospecies, and $0.28-0.48$ for plant species. Therefore, for any two land systems as little as $17 \%$ to as much as $87 \%$ of the total number of taxa recorded from the two land systems were recorded from both systems.

\section{Do biological assemblages on the same land system remain similar with increasing geographic separation?}

Standardized partial Mantel correlations (conditional on land-system type) revealed that geographic distance among all 24 sites accounted for significant variation in compositional dissimilarity for all taxonomic groups except bacterial phyla and ant genera (Table 5). Significant positive correlations revealed that as assemblages on the same land system became further apart they became increasingly different. Amounts of variation explained ranged from as little as $2.6 \%$ for ant morphospecies to as much as $15 \%$ for fly morphospecies (partial $r^{2}$, Table 5). Standardized Mantel statistics revealed the degree of correlation between compositional dissimilarity and geographical distance among the six sites within each land system. The highest correlation ( $r=0.93$ ) was for plant data from Rodges, but plant data from all other land systems returned low and nonsignificant correlations. Compositional dissimilarity of invertebrate orders and fly assemblages (families and morphospecies) showed the most consistent response to geographical distance across land systems. In each case three of the four land systems returned significant positive correlations and in each case the $P$ value for the nonsignificant land system was $<0.1$. Land systems on the unconsolidated sediments with a rich ant fauna (Corner and Rodges) returned a significant relationship, but only using morphospecies-level data. These findings demonstrate that the same invertebrate and plant assemblages may not be found at different locations on the same land system.

Statistically significant relationships between compositional dissimilarity and geographic distance resulted in a relatively high magnitude of biological change. The average proportion of invertebrate morphospecies shared between near sites ranged between 0.40 and 0.44 for Diptera and $0.46-0.48$ for ants, compared with $0.33-0.40$ for Diptera, and $0.41-0.42$ for ants at sites far apart (Table 6). Averaged across these groups and the land systems with significant distance effects (above), the magnitude of biological change equated to an $11 \%$ reduction in the proportion of shared morphospecies over an average distance of only $42 \mathrm{~km}$ (mean of 32 far distances of separation [eight for each land system, range $17.5-68.1 \mathrm{~km}$ ]; see Table 6 legend). 


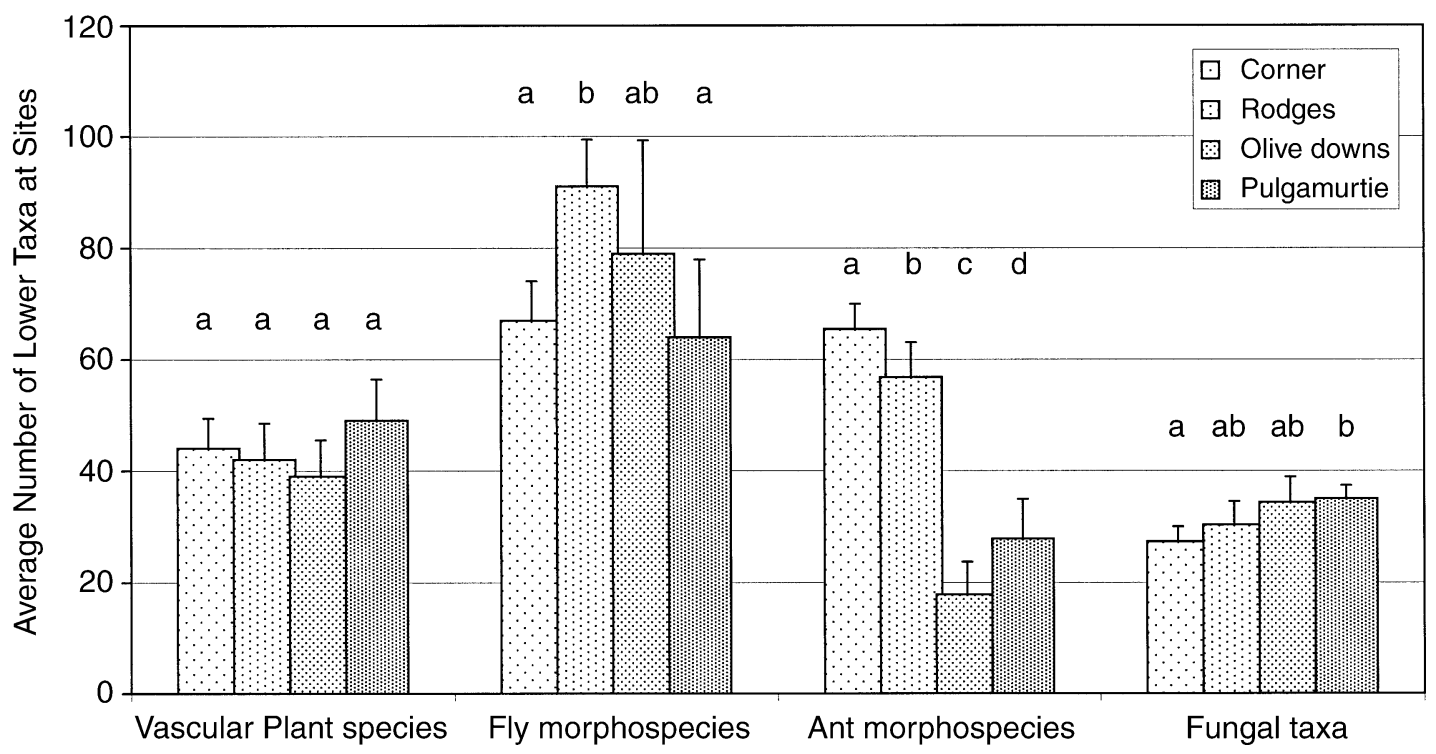

FIG. 7. Differences in assemblage richness between land systems at a fine level of taxonomic resolution. The format is as in Fig. 6.

The high correlation between compositional dissimilarity and geographic distance reported for plants on Rodges corresponded to large biological change over an average distance of only $65 \mathrm{~km}$ (mean of six far distances of separation, range $63.7-68.5 \mathrm{~km}$; see Table 6 legend). Over this geographic distance, the magnitude of biological change equated to a $41 \%$ reduction in the proportion of species shared among sites.

\section{Do biological assemblages on the same land system remain similar with increasing land system isolation?}

Least-squares regression coefficients were generated for those taxa and land systems that reported a statis- tically significant relationship between geographical distance and compositional dissimilarity (Table 7). Larger regression coefficients (steeper slope of fitted straight line) for the high-isolation land systems (Rodges and Pulgamurtie) compared with the low-isolation land systems (Corner and Olive Downs) would support the need to consider land-system isolation when using land systems as surrogates for biodiversity. Plants recorded a significant relationship for one land system only, so no test was possible. In addition, no tests were performed for ordinal data, or fly morphospecies on Olive Downs vs. Rodges, as our one-tailed test was not required when regression coefficients were higher on low-isolation land systems. Significance tests for the

TABLE 3. Statistical relationships between compositional dissimilarity and land-system type.

\begin{tabular}{|c|c|c|c|c|c|}
\hline \multirow[b]{3}{*}{ Taxon } & \multirow[b]{3}{*}{ Partial $r \dagger$} & \multicolumn{4}{|c|}{ Land-system type $\neq$} \\
\hline & & \multicolumn{2}{|c|}{$\begin{array}{l}\text { Unconsolidated } \\
\text { sediments }\end{array}$} & \multicolumn{2}{|c|}{ Cretaceous sediments } \\
\hline & & Corner & Rodges & Pulgamurtie & Olive Downs \\
\hline Bacterial phyla & $0.06^{\mathrm{NS}}$ & $\mathrm{a}$ & $\mathrm{a}$ & $\mathrm{a}$ & $\mathrm{a}$ \\
\hline Invertebrate orders & $0.37 * * *$ & $\mathrm{a}$ & $\mathrm{a}$ & $\mathrm{b}$ & $\mathrm{b}$ \\
\hline Fly families & $0.23 * * *$ & $\mathrm{a}$ & $\mathrm{b}$ & $\mathrm{c}$ & $\mathrm{d}$ \\
\hline Ant genera & $0.41 * * *$ & $\mathrm{a}$ & $\mathrm{a}$ & $\mathrm{b}$ & $\mathrm{b}$ \\
\hline Fungal ITS types & $0.20 * *$ & $\mathrm{a}$ & $\mathrm{a}$ & $\mathrm{b}$ & $\mathrm{b}$ \\
\hline Fly morphospecies & $0.42 * * *$ & $\mathrm{a}$ & $\mathrm{b}$ & $\mathrm{c}$ & $\mathrm{d}$ \\
\hline Ant morphospecies & $0.69 * * *$ & a & b & $\mathrm{c}$ & $\mathrm{d}$ \\
\hline Plant species & $0.59 * * *$ & $\mathrm{a}$ & $\mathrm{b}$ & $\mathrm{c}$ & $\mathrm{d}$ \\
\hline
\end{tabular}

$* P<0.05$; ** $P<0.01$; *** $P<0.001$; NS, $P>0.05$

$\dagger$ Standardized partial Mantel correlation between compositional dissimilarity and land-system type conditional on geographic distance among sites (Legendre and Vaudor 1991).

\$ The lowercase letters indicate significant differences between assemblages among land systems according to ANOSIM posthoc multiple comparisons (Carr 1994). Differences were statistically significant when $P<0.008$ after Bonferonni correction for post hoc multiple comparisons. That is, $P$ values were corrected to an experimentwise $\alpha=0.05$ by Bonferonni correction, $\alpha$ divided by the number of comparisons, $0.05 / 6$. 
TABLE 4. The magnitude of biological difference in taxonomic composition (at the fine level of resolution) between land systems.

\begin{tabular}{|c|c|c|c|c|c|}
\hline \multirow[b]{3}{*}{ Taxon } & \multicolumn{2}{|c|}{ Number of taxa recorded } & \multirow{2}{*}{\multicolumn{3}{|c|}{ Proportion of taxa shared§ }} \\
\hline & \multirow{2}{*}{$\begin{array}{l}\text { Within the } \\
\text { land system } \dagger\end{array}$} & \multirow{2}{*}{$\begin{array}{l}\text { Unique to a } \\
\text { land system } \neq\end{array}$} & & & \\
\hline & & & Corner & Rodges & Olive Downs \\
\hline \multicolumn{6}{|l|}{ Fungal ITS types } \\
\hline Corner & 43 & 1 & $\ldots$ & & \\
\hline Rodges & 43 & 1 & 0.72 & $\ldots$ & \\
\hline Olive Downs & 50 & 2 & 0.79 & 0.75 & $\ldots$ \\
\hline Pulgamurtie & 51 & 2 & 0.81 & 0.77 & 0.87 \\
\hline Total among & 56 & & & & \\
\hline \multicolumn{6}{|c|}{ Fly morphospecies } \\
\hline Corner & 135 & 26 & $\ldots$ & & \\
\hline Rodges & 201 & 49 & 0.41 & $\ldots$ & \\
\hline Olive Downs & 172 & 34 & 0.41 & 0.46 & $\cdots$ \\
\hline Pulgamurtie & 150 & 22 & 0.38 & 0.49 & 0.48 \\
\hline Total among & 304 & & & & \\
\hline \multicolumn{6}{|c|}{ Ant morphospecies } \\
\hline Corner & 134 & 43 & $\cdots$ & & \\
\hline Rodges & 117 & 32 & 0.42 & $\cdots$ & \\
\hline Olive Downs & 48 & 11 & 0.17 & 0.19 & $\ldots$ \\
\hline Pulgamurtie & 70 & 16 & 0.26 & 0.23 & 0.30 \\
\hline Total among & 208 & & & & \\
\hline \multicolumn{6}{|l|}{ Plant species } \\
\hline Corner & 87 & 20 & $\ldots$ & & \\
\hline Rodges & 89 & 12 & 0.48 & $\ldots$ & \\
\hline Olive Downs & 90 & 27 & 0.28 & 0.33 & $\ldots$ \\
\hline Pulgamurtie & 104 & 28 & 0.30 & 0.41 & 0.38 \\
\hline Total among & 187 & & & & \\
\hline
\end{tabular}

remaining four taxon-land system combinations (fly families-Corner vs. Pulgamurtie, Olive Downs vs. Pulgamurtie; fly morphospecies-Olive Downs vs. Pulgamurtie; and ant morphospecies-Corner vs. Rodges) found no support for the hypothesis that regression coefficients were significantly larger on high-isolation land systems (Table 7).

\section{DisCUSSION}

Biodiversity surrogates are increasingly being used to guide natural-resource management decisions. Therefore, the principal motivation for our study was to answer the broad question, "Are land systems effective surrogates for the spatial configuration of biodiversity for conservation planning?" To answer this

TABLE 5. Statistical relationships between compositional dissimilarity and geographic distance among sites; data are standardized Mantel statistics (Legendre and Vaudor 1991).

\begin{tabular}{|c|c|c|c|c|c|}
\hline \multirow[b]{2}{*}{ Taxon } & \multirow[b]{2}{*}{ Partial $r \dagger$} & \multicolumn{2}{|c|}{ Unconsolidated sediments } & \multicolumn{2}{|c|}{ Cretaceous sediments } \\
\hline & & Corner & Rodges & Olive Downs & Pulgamurtie \\
\hline Bacterial phyla & $0.02^{\mathrm{NS}}$ & $0.16^{\mathrm{NS}}$ & $-0.40^{\mathrm{NS}}$ & $-0.10^{\mathrm{NS}}$ & $-0.26^{\mathrm{NS}}$ \\
\hline Invertebrate orders & $0.24 * * *$ & $0.77^{* * *}$ & $0.34^{\mathrm{NS}}$ & $0.82 * *$ & $0.48 *$ \\
\hline Fly families & $0.26 * * *$ & $0.74 *$ & $0.37^{\mathrm{NS}}$ & $0.51 * *$ & $0.62 *$ \\
\hline Ant genera & $0.01^{\mathrm{NS}}$ & $0.24^{\mathrm{NS}}$ & $0.14^{\mathrm{NS}}$ & $0.02^{\mathrm{NS}}$ & $0.27^{\mathrm{NS}}$ \\
\hline Fungal ITS types & $0.23 * *$ & $-0.26^{\mathrm{NS}}$ & $-0.41^{\mathrm{NS}}$ & $-0.27^{\mathrm{NS}}$ & $-0.02^{\mathrm{NS}}$ \\
\hline Fly morphospecies & $0.39 * * *$ & $0.62^{\mathrm{NS}}$ & $0.70 *$ & $0.60 * *$ & $0.67 *$ \\
\hline Ant morphospecies & $0.16^{*}$ & $0.48^{*}$ & $0.52 * *$ & $0.28^{\mathrm{NS}}$ & $0.10^{\mathrm{NS}}$ \\
\hline Plant species & $0.38 * * *$ & $0.41^{\mathrm{NS}}$ & $0.93 * *$ & $0.21^{\mathrm{NS}}$ & $0.49^{\mathrm{NS}}$ \\
\hline
\end{tabular}

$* P<0.05$; ** $P<0.01$; *** $P<0.001$; NS, $P>0.05$

$\dagger$ Standardized partial Mantel correlation between compositional dissimilarity and geographic distance among sites conditional on land-system type. 
TABLE 6. The magnitude of biological change in taxonomic composition (fine taxon level) within land systems; the average proportion of taxa shared among sites within four land systems at three distance classes are shown.

\begin{tabular}{|c|c|c|c|c|}
\hline \multirow[b]{2}{*}{ Taxon } & \multicolumn{3}{|c|}{ Distance classes $†$} & \multirow{2}{*}{$\begin{array}{l}\text { Magnitude } \\
\text { of change } \\
(N-F) / F\end{array}$} \\
\hline & Near, $N$ & Medium & Far, $F$ & \\
\hline \multicolumn{5}{|c|}{ Fly morphospecies } \\
\hline Rodges & 0.44 & 0.40 & 0.39 & 0.11 \\
\hline Olive Downs & 0.41 & 0.42 & 0.40 & 0.02 \\
\hline Pulgamurtie & 0.40 & 0.39 & 0.33 & 0.18 \\
\hline \multicolumn{5}{|c|}{ Ant morphospecies } \\
\hline Rodges & 0.48 & 0.46 & 0.41 & 0.15 \\
\hline Corner & 0.46 & 0.45 & 0.42 & 0.09 \\
\hline \multicolumn{5}{|l|}{ Plant species } \\
\hline Rodges & 0.51 & 0.42 & 0.30 & 0.41 \\
\hline
\end{tabular}

Note: Only statistically significant relationships are analyzed (see Table 5).

$\dagger$ All data: Average Jaccard index, $\mathrm{SJ}=C /(A+B-C)$, where SJ is the similarity index of Jaccard, $C$ is the number of taxa shared by two sites within a land system, and $A$ and $B$ are the total number of taxa (richness) recorded from each site on that land system (Jongman et al. 1995). For invertebrates on all land systems where there were six sites, averages were calculated for distance classes as follows: near $n=3$ Jaccard indices, medium $n=4$, and far $n=8$ (see Fig. 4). For vascular plants on Rodges where there were five sites only, averages were calculated as follows: near $n=2$ Jaccard indices, medium $n=2$, and far $n=6$.

For invertebrates on all land systems, near distances of separation were $2.0-4.8 \mathrm{~km}$, medium were $9.9-22.3 \mathrm{~km}$, and far were 23.2-63.3 km (see Fig. 4). For vascular plants on Rodges, near distances of separation were 0.4 and $1.3 \mathrm{~km}$ (see Table 1), medium were 10.7 and $11.8 \mathrm{~km}$, and far were 63.7-68.5 km.

we asked three specific questions that we discuss in turn.

\section{Question 1: Do different land systems represent different biological assemblages?}

We found that the richness of ant assemblages differed among all four land systems and was higher on the unconsolidated sediments, but richness for other taxa was not significantly different among all land systems. This result adds to the growing body of evidence questioning the role of taxon richness in conservation planning (see Oliver et al. [1998] and references therein). With respect to compositional dissimilarity, we found that the four land systems represented different assemblages of ant and fly morphospecies and plant species. Up to $48 \%$ of the variation in compositional dissimilarity was accounted for by land-system type. This supports the current trend towards use of environmental surrogates of biodiversity, including land systems, for conservation planning (Mackey et al. 1989, Margules and Pressey 2000, Pressey et al. 2000, Smart et al. 2000, Cowling and Heijnis 2001, Lombard et al. 2003). However, our study did reveal that the magnitude of compositional dissimilarity among land systems was not particularly high. In other words, many taxa were shared among land systems. This pattern was most evident for the fungi, where $72-87 \%$ of ITS (internal transcribed spacer) types were shared between pairs of land systems, and least evident for the ants where only $17-42 \%$ of morphospecies were shared. These results suggest that a large proportion of the plant, arthropod, and microbial biodiversity within the region may be characterized by widespread species with relatively low fidelity to particular land-system types.

\section{Question 2: Do biological assemblages on the same land system remain similar with increasing} geographic separation?

Our study also recognized and explored the importance of geographic distance within the context of land systems as surrogates for biodiversity. Several studies have demonstrated the importance of geographic distance, between otherwise similar sites, as a predictor of differences in biological assemblages. For example, Mesibov (1993, 1998) showed that rainforest sites matched for vegetation but separated by $200 \mathrm{~km}$, held only $50 \%$ of litter invertebrate species in common (see

TABLE 7. Least-squares regression coefficients for taxon-land system combinations with significant relationships between geographic and biological distance (see Table 5).

\begin{tabular}{llllll}
\hline \hline & \multicolumn{3}{c}{ Land systems } \\
\cline { 2 - 3 } \multicolumn{1}{c}{ Taxon } & \multicolumn{2}{c}{ Low isolation } & & \multicolumn{2}{c}{ High isolation } \\
\cline { 2 - 3 } \cline { 5 - 6 } & Corner & Olive Downs & & Rodges & Pulgamurtie \\
\hline Invertebrate "orders" & $0.038 \dagger$ & $0.046 \dagger$ & & NA & 0.019 \\
Fly families & $0.063^{\mathrm{NS}}$ & $0.085^{\mathrm{NS}}$ & & $\mathrm{NA}$ & 0.112 \\
Fly morphospecies & $\mathrm{NA}$ & 0.084 & & $0.064 \dagger$ & $0.133^{\mathrm{NS}}$ \\
Ant morphospecies & 0.053 & $\mathrm{NA}$ & & $0.056^{\mathrm{NS}}$ & $\mathrm{NA}$ \\
Plant species & $\mathrm{NA}$ & $\mathrm{NA}$ & & 0.125 & NA \\
\hline
\end{tabular}

Notes: "NA" indicates that regression coefficients were not calculated because significant relationships between geographical and biological distance were not reported. Results are shown for comparison of labeled regression coefficients with the alternate low-isolation or highisolation land system; "NS" indicates that the coefficients did not differ significantly $(P>$ $0.05)$.

$\dagger$ Not tested. One-tailed test is only appropriate for comparisons in which regression coefficients are larger for high-isolation land systems. 
also Taylor et al. [1994]). Similarly, in a study by Oliver et al. (1998) differences in the composition of groundactive invertebrates were detected in otherwise-similar forests over distances of only $100 \mathrm{~km}$. In a larger study by Ferrier et al. (1999), geographic distance between sites was found to explain significant amounts of variation in the compositional dissimilarity of grounddwelling invertebrates but not for diurnal birds, reptiles, or vascular plants.

With respect to plants, recent studies by Condit et al. (2002) and Nekola and White (1999) reported significant relationships between compositional dissimilarity and geographic distance for otherwise similar sites. Condit et al. (2002) used the Jaccard index, among others, to measure the similarity in tree-morphospecies composition between plots and explored the decay in similarity with geographic distance. Within Peru and Ecuador, adjacent plots shared only 55\% of their species, and biological similarity declined rapidly with distances up to $3-5 \mathrm{~km}$. Interestingly, similarity changed little from 5 to $100 \mathrm{~km}$, with plots at these distances consistently sharing 30-40\% of their species (see also Felfili and Da Silva 1993, Keith 1995). Nekola and White (1999) conducted a similar study over a larger spatial scale and used both vascular-plant and nonvascular-plant data from plots distributed throughout largely continuous boreal forest from Newfoundland to Alaska (plots separated by $<100 \mathrm{~km}$ to $>5000$ $\mathrm{km})$. Those authors also used the Jaccard index and found that similarity decreased significantly with distance for both vascular-plant and nonvascular-plant data. They also showed that the rate of similarity decay was 1.5-1.9 times higher for the vascular plants than for the nonvascular plants.

Our data revealed similar significant positive correlations between geographic distance and compositional dissimilarity, and suggested that the magnitude of biological change over relatively short distances within a land system may be large and sufficient to warrant the consideration of geographical distance in assessments of land systems as surrogates for biodiversity. As with the findings of Ferrier et al. (1999), the invertebrates were the most consistent with respect to this relationship. Our results were somewhat equivocal with respect to the vascular plants. Three out of the four land systems showed no relationships between biological and geographic distance, yet the fourth (Rodges) revealed both the highest standardized Mantel statistic (0.93) and the highest magnitude of biological change ( $41 \%$ reduction in the number of shared species over an average distance of only $65 \mathrm{~km}$ ). The lack of a general relationship between plant assemblages and distance may be explained by the methods used to map land systems. Land-system classifications were developed from 1:50000 stereo air-photo interpretation of recurring patterns of topography, geology, soil, and vegetation. The a priori incorporation of vegetation pattern into the process of mapping land systems may therefore have already accounted for some of the variation in plant assemblages resulting from geographic separation on otherwise similar topography, geology, and soils. This explanation does not, however, account for the significant result observed for the Rodges land system. Further analyses underway by R. L. Pressey and V. Logan using a larger vascular-plant data set from the same region may shed light on our results for vascular plants.

\section{Question 3: Do biological assemblages on the same land system remain similar with increasing land-system isolation?}

The study by Nekola and White (1999) also presented analyses of a data set for Appalachian montane spruce-fir forests restricted to high mountain peaks. These montane forest plots were, therefore, isolated from each other by the upland and lowland forests at lower altitudes. They showed that the rate of similarity decay was 2.7 times higher for floras from the isolated Appalachians than for their other data set for floras from the continuous boreal forests. In contrast to these findings, our study did not reveal higher rates of decay in similarity for our high-isolation land systems Rodges and Pulgamurtie, when compared with our low-isolation land systems Corner and Olive Downs. Compared with our study, Nekola and White's was on a larger spatial scale and the climate differences between their mountain peaks and lowlands were undoubtedly far greater than any differences between our high-isolation and low-isolation land systems. Our results, therefore, show that although mapped as isolated land systems, from a biological perspective Pulgamurtie and Rodges were not isolated but were well connected. This is supported by our analyses of data for Question 1 where we found considerable biological overlap among assemblages from different land systems, and as a result suggested that a large proportion of the plant, arthropod, and microbial biodiversity within the region may be characterized by widespread taxa with relatively low fidelity to particular land-system types.

\section{Application of findings to conservation planning}

Spatial structure in biological data is a common phenomenon. Studies concerned with spatial autocorrelation either as the variable of interest (Burgman and Williams 1995, Peakall and Beattie 1995, He et al. 1996, Barange and Hampton 1997) or as a variable to be partitioned out of analyses more interested in other explanatory variables (Borcard et al. 1992, Borcard and Legendre 1994) are abundant (see also Legendre and Fortin 1989, Legendre 1993, Tilman and Kareiva 1997). The subject continues to generate much interest (e.g., special journal issues, [Collinge 2001] and conference symposia [J. C. Nekola and H. Wagner, unpublished manuscript]). Explanations for spatial patterns in the composition of assemblages can be found in both deterministic or environmental models (climate, 
geology, soils, disturbance) and stochastic or biological models (evolutionary history, dispersal, species interactions; see May 1984, Nekola and White 1999, Pyke et al. 2001). However, it is only very recently that studies have begun to explore the independent and interactive roles of deterministic and stochastic drivers of the composition of assemblages (Pyke et al. 2001, Ettema and Wardle 2002). Our study, together with those cited in this discussion, provides strong evidence of the importance of both deterministic and stochastic drivers of differences in species composition among sites. We have demonstrated that as much as $48 \%$ of the variation in assemblages can be explained by landsystem differences (deterministic model) and as much as $15 \%$ by geographic separation among sites with few environmental differences (stochastic model). Differences between biological assemblages occupying similar but geographically distant habitats, variously referred to as "gamma" or "delta" diversity (see references cited within Ferrier [2002]), are critically important to the application of biodiversity surrogates to conservation planning.

One notable example of application of both deterministic and stochastic models to conservation planning is a recent conservation assessment for the Cobar Peneplain biogeographic region in New South Wales (NSW), Australia, conducted by the NSW National Parks and Wildlife Service (Dick 2000, Smart et al. 2000). The aim of the assessment was to develop and apply a systematic approach to identifying a potential network of sites that reasonably represented the biotic diversity of the region. The Cobar Peneplain is one of 80 biogeographic regions identified across the Australian continent, with each representing groups of ecosystems classified by their most dominant landscape features such as climate, geology, landform and vegetation (Thackway and Cresswell 1995). The Cobar Peneplain is large, occupying $73500 \mathrm{~km}^{2}$, has undergone loss of native vegetation and wildlife habitat, is poorly represented in the State's protected-areas network, and is under increasing pressure from land-holders wishing to extend clearing practices further westward into the more arid parts of the region (Smart et al. 2000). The National Parks and Wildlife Service's conservation assessment used land systems as the surrogate for biodiversity. However, many of the land systems extended (either continuously or discontinuously) across hundreds of kilometers. A subdivision of the bioregion into five provinces (larger than land systems but contained within the bioregion), based largely on Morgan and Terrey (1992), was used to account for the variability in biodiversity within the same land system across large geographic distances. That is, the original 87 land systems as mapped for the bioregion by Walker (1991) and NSW NPWS (2000) were partitioned into their respective provinces, resulting in a new total of 136 land systems, and it was these 136 "refined land systems" that were used for the final conservation assessment.

\section{The importance of taxonomic resolution}

In this study we employed very different taxonomic scales and techniques across an unusually broad spectrum of biota and over relatively large spatial scales. Our failure to observe microbial-assemblage differences among land systems may well be due to current technological limitations and the use of higher taxa or a "coarse-filter" approach to biodiversity assessment (Noss 1987). The higher-taxa data sets, invertebrate orders (33 taxa), fly families (36 taxa), and ant genera (23 taxa) can also be considered a coarse-filter approach to biodiversity assessment. The coarse-scale nature of such biological units used to characterize biodiversity will obviously influence interpretation of the spatial patterns observed. Higher taxa are phylogenetically older taxa. To the extent that any higher taxon represents a biological unit, it represents a unit that has had a longer period of time to experience and adapt to, and therefore be present in, a range of different environments. Assemblages of such higher taxa, or coarsefilters, may therefore be expected to only reflect coarsescale environmental differences. This was the case for invertebrate orders, ant genera, and fungal ITS types that distinguished among land systems from different geologies (unconsolidated sediments from Cretaceous sediments) but did not distinguish between land systems within geologies (Table 3 ). In comparison, “finefilter" data sets are likely to have greater ability to reflect more subtle environmental differences. Our finefilter data sets (ant and fly morphospecies and plant species) did reveal differences in assemblages among all land systems studied. The decision of on which taxonomic scale to use for investigations of environmental surrogates for biodiversity is therefore closely related to the expected or known variation in the particular surrogate of interest. The issue of taxonomic scale, or resolution, is clearly an important consideration in assessments of biodiversity and reinforces the need to ensure that the taxonomic scale of study is appropriate to the question(s) asked of the data (Pik et al. 1999).

Despite the limitations discussed above, our bacterial biodiversity assessment revealed that half of the specimens we recovered were identified with the probe set. Sequence analysis of randomly selected representatives of the unidentified clones showed that a large proportion of the unidentified specimens represented yet-tobe-cultured organisms that constitute multiple new phyla of low abundance relative to the groups counted (A. Holmes, unpublished data). Only two known bacterial phyla, the beta-Proteobacteria and Verrucomicrobiales were relatively abundant among the unidentified clones. There was, therefore, significant information on bacterial biodiversity remaining in the samples that we were unable to assess with the available 
probe set. It is possible that these low-abundance yetto-be-cultured organisms may show very different spatial patterns compared to the more common taxa. Our investigations are ongoing into the spatial configuration of the rich microbial biodiversity contained within our samples from these arid Australian soils (Holmes et al. 2000).

\section{Conclusion}

Our study provides empirical data in support of environmental surrogates for biodiversity-specifically the use of land systems and similarly derived land classifications-in conservation planning. Each of the land systems studied supported components of biodiversity not found, or found infrequently, on other land-system types, suggesting that conservation-area networks that represent land-system diversity are also likely to be representative of biodiversity. The majority of taxa were, however, found on more than one land-system type. Importantly, our present study's findings, as with those of the others discussed, strongly suggests that conservation planning based on land-system diversity should also aim to sample the geographic space occupied by each land system. Investigations that endeavor to study the independent and interactive roles of deterministic (environmental) and stochastic (biological) drivers of biodiversity (see Ferrier 2002, Ferrier et al. 2002b) promise further insights into how the planet's biological wealth is distributed, as well as better tools to assist in planning for its persistence.

\section{ACKNOWLEDGMENTS}

Field work for this project could not have been completed within the desired timeframe without the assistance of an enthusiastic and dedicated team of volunteers. We would like to thank Christine Baker, Roger Bramble, David Briscoe, Bradley Croft, Robyn Delves, Helen Doherty, Rebecca Harris, Martin Henery, Matthew McConnachie, Chris Myles, Nicola Oram, Graham Osler, Miriam Struelens, Jaynia Tarnowski, Matthew Taylor, Niina Tujula, Marion Wilkinson, and Michelle Williams for their untiring assistance under sometimes very trying conditions. NSW NPWS (Tibooburra) were a wealth of information and provided assistance in all aspects of the project. They also went to great lengths to provide us with on-site accommodation and work sheds for which we are truly grateful. Special thanks to Bronwyn Johnson, Louise Christie and Lars Kogge. Invertebrate morphospecies verification by the specialists Alan Andersen (CSIRO Division of Wildlife and Ecology, Darwin), Brian Heterick (Curtin University of Technology, Western Australia), and Dan Bickel (Australian Museum, Sydney), was critical to the success of this project. Aaron Colbran from the Department of Land and Water Conservation kindly supplied Figs. 1 and 2. Comments from David Briscoe, Richard Condit, David Eldridge, Jessica Green, John Ludwig, and Mark Westoby improved earlier versions of the manuscript. Reviews by Simon Ferrier and one anonymous reviewer improved the submitted version of the manuscript. The project was funded by the Resource and Conservation Assessment Council of NSW and the Key Centre for Biodiversity and Resources, Macquarie University. This paper is contribution number 386 to the Key Centre for Biodiversity and Bioresources.

\section{Literature Cited}

Allison, G. B., P. G. Cook, S. R. Barnett, G. R. Walker, I. D. Jolly, and M. W. Hughes. 1990. Land clearance and river salinisation in the western Murray basin, Australia. Journal of Hydrology 119:1-20.

Barange, M., and I. Hampton. 1997. Spatial structure of cooccuring anchovy and sardine populations from acoustic data: implications for survey design. Fisheries Oceanography 6:94-108.

Benson, J. 1991. The effect of 200 years of European settlement on the vegetation and flora of New South Wales. Cunninghamia 2:342-370.

Borcard, D., and P. Legendre. 1994. Environmental control and spatial structure in ecological communities: an example using oribatid mites (Acari, Oribatei). Environmental and Ecological Statistics 1:37-61.

Borcard, D., P. Legendre, and P. Drapeau. 1992. Partialling out the spatial component of ecological variation. Ecology 73:1045-1055.

Burgman, M. A., and M. R. Williams. 1995. Analysis of the spatial pattern of arthropod fauna of jarrah (Eucalyptus marginata) foliage using a Mantel correlogram. Australian Journal of Ecology 20:455-457.

Carr, M. R. 1994. Plymouth routines in multivariate ecological research. Plymouth Marine Laboratory, Plymouth, UK.

Christian, C. S. 1958. The concept of land units and land systems. Pages 74-81 in Proceedings of the Ninth Pacific Science Congress (1957) 20.

Clarke, K. R., and R. M. Warwick. 2001. Change in marine communities: an approach to statistical analysis and interpretation. Second edition. PRIMER-E, Plymouth, England.

Cole, J. R., B. Chai, T. L. Marsh, R. J. Farris, Q. Wang, S. A. Kulam, S. Chandra, D. M. McGarrell, T. M. Schmidt, G. M. Garrity, and J. M. Tiedje. 2003. The Ribosomal Database Project (RDP-II): previewing a new autoaligner that allows regular updates and the new prokaryotic taxonomy. Nucleic Acids Research 31:442-443.

Collinge, S. K. 2001. Spatial ecology and biological conservation. Biological Conservation 100:1-2.

Colwell, R. K. 1996. Biota. The biodiversity database manager. Sinauer Associates, Sunderland, Massachusetts, USA.

Condit, R., N. Pitman, E. G. Leigh, Jr., J. Chave, J. Terborgh, R. B. Foster, P. V. Núñez, S. Aguilar, R. Valencia, G. Villa, H. Muller-Landau, E. Losos, and S. P. Hubbell. 2002. Betadiversity in tropical forest trees. Science 295:666-669.

Cowling, R. M., and C. E. Heijnis. 2001. The identification of Broad Habitat Units as biodiversity entities for systematic conservation planning in the Cape Floristic Region. South African Journal of Botany 67:15-38.

Day, R. W., and G. P. Quin. 1989. Comparisons of treatments after an analysis of variance in ecology. Ecological Monographs 59:433-463.

Dick, R. 2000. A multi-faceted approach to regional conservation assessment on the Cobar Peneplain bioregionan overview. NSW National Parks and Wildlife Service, Sydney, New South Wales, Australia.

Dickman, C. R., R. L. Pressey, L. Lim, and H. A. Parnaby. 1993. Mammals of particular conservation concern in the Western Division of New South Wales. Biological Conservation 65:219-248.

Ettema, C. H., and D. A. Wardle. 2002. Spatial soil ecology. Trends in Ecology and Evolution 17:177-183.

Fauth, J. E., J. Bernardo, M. Camara, W. J. Resetarits, Jr., J. Van Buskirk, and S. A. McCollum. 1996. Simplifying the jargon of community ecology: a conceptual approach. American Naturalist 147:282-286.

Felfili, J. M., and M. C. Da Silva, Jr. 1993. A comparative study of cerrado (sensu stricto) vegetation in Central Brazil. Journal of Tropical Ecology 9:277-289. 
Ferrier, S. 2002. Mapping spatial pattern in biodiversity for regional conservation planning: where to from here? Systematic Biology 51:331-363.

Ferrier, S., M. Drielsma, G. Manion, and G. Watson. $2002 b$. Extended statistical approaches to modelling spatial pattern in biodiversity in northeast New South Wales. II. Community-level modelling. Biodiversity and Conservation 11: 2309-2338.

Ferrier, S., M. R. Gray, G. A. Cassis, and L. Wilke. 1999. Spatial turnover in species composition of ground-dwelling arthropods, vertebrates and vascular plants in north-east New South Wales: implications for selection of forest reserves. Pages 68-76 in W. Ponder and D. Lunney, editors. The other 99\%: the conservation and biodiversity of invertebrates. Transactions of the Royal Zoological Society of New South Wales, Sydney, New South Wales, Australia.

Ferrier, S., and G. Watson. 1997. An evaluation of the effectiveness of environmental surrogates and modelling techniques in predicting the distribution of biological diversity. Environment Australia, Canberra, Australian Capital Territory, Australia.

Ferrier, S., G. Watson, J. Pearce, and M. Drielsma. $2002 a$. Extended statistical approaches to modelling spatial pattern in biodiversity in northeast New South Wales. I. Specieslevel modelling. Biodiversity and Conservation 11:22752307.

Fromin, N., J. Hamelin, S. Tarnawski, D. Roesti, K. JourdainMiserez, N. Forestier, S. Teyssier-Cuvelle, F. Gillet, M. Aragno, and P. Rossi. 2002. Statistical analysis of denaturing gel electrophoresis (DGE) fingerprinting patterns. Environmental Microbiology 4:634-643.

Garrity, G. M., and J. G. Holt. 2001. Taxonomic outline of the Archaea and Bacteria. Pages 155-166 in D. R. Boone and R. W. Castenholz, editors. Bergeys manual of systematic bacteriology. Second edition. Springer-Verlag, New York, New York, USA.

Graham, O. P. 1992. Survey of land degradation in New South Wales, Australia. Environmental Management 16:205-223.

He, F., P. Legendre, and J. V. LaFrankie. 1996. Spatial pattern of diversity in a tropical rain forest in Malaysia. Journal of Biogeography 23:57-74.

Head, I. M., J. R. Saunders, and R. W. Pickup. 1998. Microbial evolution, diversity, and ecology: a decade of ribosomal RNA analysis of uncultivated microorganisms. Microbial Ecology 35:1-21.

Holmes, A. J., J. Bowyer, M. P. Holley, M. O'Donoghue, M. Montgomery, and M. R. Gillings. 2000. Diverse, yet-tobe-cultured members of the Rubrobacter subdivision of the Actinobacteria are widespread in Australian arid soils. FEMS Microbiology Ecology 33:111-120.

Hope, A. C. A. 1968. A simplified Monte Carlo significance test procedure. Journal of the Royal Statistical Society Series B 30:582-598.

James, C. D., J. Landsberg, and S. R. Morton. 1999. Provision of watering points in the Australian arid zone: a review of effects on biota. Journal of Arid Environments 41:87-121.

Johnston, P. W., P. R. Tannock, and I. F. Beale. 1996. Objective "safe" grazing capacities for southwest Queensland, Australia: model application and evaluation. Rangeland Journal 18:259-269.

Jongman, R. H. G., C. J. F. ter Braak, and O. F. R. van Tongeren, editors. 1995. Data analysis in community ecology and landscape ecology. Cambridge University Press, Cambridge, UK.

Kazaklis, A., and M. Karteris. 1993. Landscape types: patterns and relationships with abiotic landscape features in Western Crete. Landscape Urban Planning 24:249-257.

Keith, D. 1995. How similar are geographically separated stands of the same vegetation formation? A moorland ex- ample from Tasmania and Mainland Australia. Proceedings of the Royal Society of New South Wales 115:61-75.

King, R. B. 1994. The value of ground resolution, spectral range and stereoscopy of satellite imagery for land system and land use mapping of the humid tropics. International Journal of Remote Sensing 15:521-530.

Kirkpatrick, J. B., and M. J. Brown. 1994. A comparison of direct and environmental domain approaches to planning reservation of forest higher plant communities and species in Tasmania. Conservation Biology 8:217-224.

Lawrence, C. J., R. J. Byard, and P. J. Beavan. 1993. Terrain evaluation Manual. Her Majesty's Stationery Office, London, UK.

Legendre, P. 1993. Spatial autocorrelation: Trouble or new paradigm? Ecology 74:1659-1673.

Legendre, P., and M. Fortin. 1989. Spatial pattern and ecological analysis. Vegetatio 80:107-138.

Legendre, P., and A. Vaudor. 1991. The R package: multidimensional analysis, spatial analysis. Department of $\mathrm{Bi}-$ ological Sciences, University of Montreal, Montreal Québec, Canada.

Lindenmayer, D. B., A. D. Manning, P. L. Smith, H. P. Possingham, J. Fischer, I. Oliver, and M. A. McCarthy. 2002. The focal species approach and landscape restoration: a critique. Conservation Biology 16:338-345.

Lombard, A. T., R. M. Cowling, R. L. Pressey, and A. G. Rebelo. 2003. Effectiveness of land classes as surrogates for species in conservation planning for the Cape Floristic Region. Biological Conservation 112:45-62.

Mabbutt, J. A. 1968. Review of concepts of land classification. Pages 11-28 in G. A. Stewart, editor. Land evaluation. MacMillan, Melbourne, Victoria, Australia.

Mackey, B. G., H. A. Nix, J. A. Stein, and S. E. Cork. 1989. Assessing the representativeness of the wet tropics of Queensland World Heritage Property. Biological Conservation 50:279-303.

Margules, C. R., and R. L. Pressey. 2000. Systematic conservation planning. Nature 405:243-253.

May, R. M. 1984. An overview: real and apparent patterns in community structure. Pages 3-16 in D. R. Strong, D. Simberloff, L. G. Abele, and A. B. Thistle, editors. Ecological communities: conceptual issues and the evidence. Princeton University Press, Princeton, New Jersey, USA.

Mesibov, R. 1993. Species-level comparison of litter invertebrates from three vegetation types in north-west Tasmania. Tasmanian National Rainforest Conservation Program, Technical Report Number 13. Department of Environment, Sport and Territories, Canberra, Australian Capital Territory, Australia.

Mesibov, R. 1998. Species-level comparison of litter invertebrates at two rainforest sites in Tasmania. Tasforests 10: 141-157.

Mitchell, P. B. 1991. Historical perspectives on some vegetation and soil changes in semi-arid New South Wales. Vegetatio 91:169-182.

Morgan, G., and J. Terrey. 1992. Nature conservation in western NSW. National Parks Association of NSW, Sydney, New South Wales, Australia.

Murgan, R. P. C., R. J. Rickson, K. McIntyrek, T. R. Brewer, and H. J. Altshul. 1998. Soil erosion survey of the central part of the Swaziland Middleveld. Soil Technology 11:263289.

Nekola, J. C., and P. S. White. 1999. The distance decay of similarity in biogeography and ecology. Journal of Biogeography 26:867-878.

Noss, R. F. 1987. From plant communities to landscapes in conservation inventories: a look at the Nature Conservancy (USA). Biological Conservation 41:11-37.

NSW NPWS [New South Wales National Parks and Wildlife Service]. 1996. Sturt National Park: plan of management. 
New South Wales National Parks and Wildlife Service, Sydney, New South Wales, Australia.

NSW NPWS [New South Wales National Parks and Wildlife Service]. 2000. Land systems of the Cargelligo and Narrandera Sheets. New South Wales National Parks and Wildlife Service, Sydney, New South Wales, Australia.

Oliver, I., and A. J. Beattie. 1993. A possible method for the rapid assessment of biodiversity. Conservation Biology 7: 562-568.

Oliver, I., and A. J. Beattie. 1996a. Designing a cost-effective invertebrate survey: a test of methods for rapid assessment of biodiversity. Ecological Applications 6:594-607.

Oliver, I., and A. J. Beattie. 1996b. Invertebrate morphospecies as surrogates for species: a case study. Conservation Biology 10:99-109.

Oliver, I., A. J. Beattie, and A. York. 1998. Spatial fidelity of plant, vertebrate, and invertebrate assemblages in multiple-use forest in eastern Australia. Conservation Biology 12:822-835.

Oliver, I., A. Pik, D. Britton, J. M. Dangerfield, R. K. Colwell, and A. J. Beattie. 2000. Virtual biodiversity assessment systems: the application of bioinformatics technologies to the accelerated accumulation of biodiversity information. BioScience 50:441-450.

Peakall, R., and A. J. Beattie. 1995. Does ant dispersal of seeds in Sclerolaena diacantha (Chenopodiaceae) generate local spatial genetic structure? Heredity 75:351-361.

Pickard, J. 1991. Land management in semi-arid environments of New South Wales. Vegetatio 91:191-208.

Pickard, J., and E. H. Norris. 1994. The natural vegetation of north-western New South Wales: notes to accompany the 1:1000000 vegetation map sheet. Cunninghamia 3: $423-464$

Pik, A. J., I. Oliver, and A. J. Beattie. 1999. Taxonomic sufficiency in ecological studies of terrestrial invertebrates. Australian Journal of Ecology 24:555-562.

Pressey, R. L. 1994. Land classifications are necessary for conservation planning but what do they tell us about the fauna? Pages 31-41 in D. Lunney, S. Hand, P. Reed, and D. Butcher, editors. Future of the fauna of western New South Wales. Royal Zoological Society of New South Wales, Sydney, New South Wales, Australia.

Pressey, R. L., T. C. Hager, K. M. Ryan, J. Schwarz, S. Wall, S. Ferrier, and P. M. Creaser. 2000. Using abiotic data for conservation assessments over extensive regions: quantitative methods applied across New South Wales. Biological Conservation 96:55-82.

Pressey, R. L., and K. H. Taffs. 2001a. Scheduling conservation action in production landscapes: priority areas in western New South Wales defined by irreplaceability and vulnerability to vegetation loss. Biological Conservation 100:355-376.

Pressey, R. L., and K. H. Taffs. 2001b. Sampling of land types by protected areas: three measures of effectiveness applied to western New South Wales. Biological Conservation 101:105-117.

Purdie, R. W., R. Blick, and M. P. Bolton. 1986. Selection of a conservation reserve network in the Mulga Biogeographic Region of south-western Queensland, Australia. Biological Conservation 38:369-384.

Pyke, C. R., R. Condit, S. Aguilar, and S. Lao. 2001. Floristic composition across a climatic gradient in a neotropical lowland forest. Journal of Vegetation Science 12:553-566.

Smart, J. M., A. T. Knight, and M. Robinson. 2000. A conservation assessment for the Cobar Peneplain Biogeographic Region-methods and opportunities. NSW National Parks and Wildlife Service, Sydney, New South Wales, Australia.

Smith, P. J., R. L. Pressey, and J. E. Smith. 1994. Birds of particular conservation concern in the Western Division of New South Wales. Biological Conservation 69:315-338.

Smouse, P. E., J. C. Long, and P. R. Sokal. 1986. Multiple regression and correlation extensions of the Mantel test of matrix correspondence. Systematic Zoology 35:627-632.

Taylor, R. J., R. Mesibov, and I. Growns. 1994. Local distribution patterns of land snails in relation to vegetation: implications for reserve design. Memoirs of the Queensland Museum 36:215-220.

Thackway, R., and I. D. Cresswell. 1995. An interim biogeographic regionalisation for Australia: a framework for establishing the national system of reserves. Version 4. Australian Nature Conservation Agency, Canberra, Australian Capital Territory, Australia.

Tilman, D., and P. Kareiva, editors. 1997. Spatial ecology: the role of space in population dynamics and interspecific interactions. Princeton University Press, Princeton, New Jersey, USA.

Underwood, A. J. 1995. GMAV5: 5 factor analysis of variance program. Institute of Marine Ecology, Sydney University, Sydney, New South Wales, Australia.

Van Wilgen, B. W., H. C. Biggs, S. P. O'Regan, and N. Mare. 2000. A fire history of the savanna ecosystems in the Kruger National Park, South Africa, between 1941 and 1996. South African Journal of Science 96:167-183.

Walker, P. J. 1991. Land systems of western New South Wales. Technical Report Number 25. Soil Conservation Service of New South Wales, Sydney, New South Wales, Australia.

Wessels, K. J., S. Freitag, and A. S. van Jaarsveld. 1999. The use of land facets as biodiversity surrogates during reserve selection at the local scale. Biological Conservation 89:2138 .

Wilson, E. O. 1987. The little things that run the world. Conservation Biology 1:342-346.

Yeates, C., and M. R. Gillings. 1998. Rapid purification of DNA from soil for molecular biodiversity analysis. Letters in Applied Microbiology 27:49-53.

Zar, J. H. 1984. Biostatistical analysis. Second edition. Prentice-Hall, Englewood Cliffs, New Jersey, USA. 